\title{
Fate and Transport of Hydrophobic Organic Chemicals in the Lower Passaic River: Insights from 2,3,7,8- Tetrachlorodibenzo-p-Dioxin
}

\author{
Peter H. Israelsson • James D. Quadrini • \\ John P. Connolly
}

Received: 26 February 2013 /Revised: 25 November 2013 / Accepted: 16 December 2013 /Published online: 1 May 2014

(C) The Author(s) 2013. This article is published with open access at Springerlink.com

\begin{abstract}
The fate and transport of hydrophobic organic chemicals (HOCs) is particularly complex in estuaries because of bidirectional longitudinal currents, density stratification, the tendency to trap sediments, and significant dilution in the downstream bay or ocean. Investigations of HOCs in estuaries are further complicated because HOCs typically enter from multiple sources. The distribution of contaminants in estuarine sediment beds reflect a time integration of a complex balance of time- and space-variable fate and transport processes and loading history. A unique opportunity to study HOC fate and transport exists in the Lower Passaic River (LPR), where a pesticide manufacturer was the dominant source of 2,3,7,8-tetrachlorodibenzo-p-dioxin (2,3,7,8TCDD) to the estuary and the distribution of this "tracer of opportunity" provides insights about fate and transport processes in estuarine systems. This paper presents observed sediment 2,3,7,8-TCDD patterns within the LPR and the adjacent Newark Bay, and interprets them in terms of fate and transport processes that likely distributed the contaminant from its dominant source, drawing upon other physical datasets as needed. Major observations include that estuarine transport processes have distributed 2,3,7,8-TCDD approximately $18 \mathrm{~km}$ upstream of the source and downstream across
\end{abstract}

Communicated by Sid Mitra

P. H. Israelsson $(\bowtie)$

Anchor QEA, LLC, 10 Liberty Square, 6th Floor, Boston,

MA 02109, USA

e-mail: pisraelsson@anchorqea.com

J. D. Quadrini · J. P. Connolly

Anchor QEA, LLC, 305 West Grand Ave, Suite 300, Montvale,

NJ 07645, USA

\author{
J. D. Quadrini \\ e-mail: jquadrini@anchorqea.com \\ J. P. Connolly \\ e-mail: jconnolly@anchorqea.com
}

Newark Bay, and that, generally, HOC trapping processes within the LPR have been highly effective, particularly near the 2,3,7,8-TCDD source and in downstream areas. The present LPR surface sediment 2,3,7,8-TCDD distribution indicates spatially variable recovery, which appears broadly driven by historical net sedimentation patterns, though the dominant processes may be shifting as the system continues to evolve.

Keywords Estuary $\cdot$ Tracer $\cdot$ Sediment $\cdot$ HOC $\cdot$ Fate $\cdot$ Transport · Passaic

\section{Introduction}

The study of contaminated sediments in estuaries is complex because any original source will likely have contributed to contamination both upstream (landward) and downstream (seaward) of its location. The extent of upstream influence is particularly vexing because of the variations in upstream transport that occur over the range of freshwater flows entering the estuary, the variations in tidal forcing and salinity gradients, and the longitudinal variations in cross-section that are characteristic of most estuaries. Moreover, the fate of sediment-associated contaminants is tied to the movement of unconsolidated sediments that migrate with the tides and interact with an underlying parent sediment bed. This "mobile pool" of sediments (Geyer 1993) can enhance the migration of the contaminant and control its disposition within the estuary and its release from the estuary to downstream areas. A unique opportunity to study hydrophobic organic chemical (HOC) fate and transport exists in the Lower Passaic River (LPR), where a pesticide manufacturer was the dominant source of 2,3,7,8-tetrachlorodibenzo- $p$-dioxin $(2,3,7,8$-TCDD) to the estuary and the spatial distribution of this "tracer of 
opportunity" provides insights about fate and transport processes in estuarine systems.

The LPR is a 17.4-mile ${ }^{1}$-long, partially mixed estuary located in the northeastern USA (New Jersey), extending from Dundee Dam to Newark Bay (Fig. 1). Freshwater inputs are composed primarily of inflows from the Upper Passaic River (UPR) at Dundee Dam and three LPR tributaries (Saddle River, Third River, and Second River), with secondary contributions from smaller tributaries, combined sewer overflows (CSOs), stormwater outfalls, municipal and industrial discharges, and direct stormwater runoff. The salinity field of the LPR responds strongly to the freshwater flow and tidal forcing, as demonstrated by recent field studies presented in Chant et al. (2011), in which the salt front reached approximately 11 miles upstream of the mouth under extreme low flow conditions and was pushed into Newark Bay under extreme high flow conditions. Likewise, flow, tide and density forcings strongly influence sediment transport, favoring a net upstream solids transport during low flow conditions (due to tidal pumping and gravitational circulation), which transitions to a more intense downstream transport during high flow events, with solids export to Newark Bay (Chant et al. 2011; Sommerfield and Chant 2010). Given the long-term solids trapping and sediment redistribution associated with these dynamics, HOC transport in the LPR is likewise expected to exhibit both short-term dynamics and long-term trends, with the latter being the focus of the present study.

Like other urban rivers, the LPR has received a broad range of contaminants from a multitude of direct and indirect sources. Contaminant loadings to the lower 8 miles of the LPR are thought to have been most severe, encompassing the Ironbound District, "Chemical Row"," as well as most of the 36 CSOs discharging to the system (Cunningham 1966; Huntley et al. 1995; Iannuzzi et al. 1997; Shear et al. 1996). Among the most publicized industrial sources was the Diamond Alkali facility located at 80 and 120 Lister Avenue (hereinafter referred to as the Lister Avenue site) in Newark near river mile (RM; see footnote 1) 3.1 (i.e., 3.1 miles upstream of the LPR mouth), which manufactured pesticides, herbicides, and the military defoliant Agent Orange from the 1940s through the 1960s (additional details provided below). The Lister Avenue site is widely considered to be the

\footnotetext{
${ }^{1}$ The ongoing investigations of the LPR use river miles (RMs) rather than river kilometers to indicate longitudinal position. Consequently, the present study adopts the RM convention for clarity, and for internal consistency, longitudinal distances are reported in miles rather than kilometers. Moreover, we employ the river mile definition used in LPR RI/FS contexts, which differs slightly from the US Army Corps of Engineers (USACE) definition in terms of reference datum and centerline. An approximate conversion is to subtract 0.25 miles from USACE reported river miles, although the actual conversion varies slightly along the river. ${ }^{2}$ An area along the LPR with particularly dense industrial development, including tanneries as well as paint, metallurgical, and chemical manufacturers (Huntley et al. 1995; Cunningham 1966).
}

dominant historical source of 2,3,7,8-TCDD to the watershed, as well as a significant historical source of pesticides such as dichlorodiphenyltrichloroethane (DDT). While discharges to the LPR and the watershed declined following the 1972 Federal Water Pollution Control Act amendments and subsequent regulations, the LPR remains out of compliance with federal and state water quality criteria and standards for a multitude of pollutants; consequently, total maximum daily loads are being developed for nutrients and toxics. In 1984, the Lister Avenue site was listed on the Superfund National Priorities List (NPL), and Remedial Investigation/Feasibility Study (RI/FS) processes are ongoing in the LPR and Newark Bay.

Widespread infilling of native wetland areas and narrowing of the channel accompanied development, and as a result, the LPR is a channelized river dominated by hardened shorelines (e.g., bulkheads, wharves, riprap), especially in the lower 6 to 8 miles (Huntley et al. 1995; Iannuzzi et al. 2002; MPI 2007). Major historical developments include the completion of the Dundee Dam in 1858 and the subsequent expansion of regional shipping activities in the early twentieth century (Iannuzzi et al. 2002). The Greater Newark Bay Complex (i.e., Newark Bay and its tributaries, including the LPR and the Hackensack River to the north, and Kill van Kull and Arthur Kill to the south) has been engineered to support shipping, including a federal navigation channel in the LPR created between 1884 and the late 1920s, which extended up to RM 15 (USACE 2010). ${ }^{3}$ However, navigation channel maintenance dredging upstream of approximately RM 1.9 mostly ceased by 1950 (Fig. 2) ${ }^{4}$ with the development of Port Elizabeth, and was last performed downstream of RM 1.7 in 1983 (Chant et al. 2011; Iannuzzi et al. 2002; USACE 2010). Widespread infilling of the navigation channel in the lower 8 miles since the cessation of maintenance dredging is generally indicated by the elevation of the present-day sediment surface relative to the authorized channel depths (Fig. 2), although bathymetric surveys indicate that the actual depth of dredging was variable and in most cases deeper due to overdredging.

The LPR has been an effective trap of both sediments and hydrophobic contaminants (Chant et al. 2011; Huntley et al. 1995; Bopp et al. 1991, 1998; Chaky 2003). Chant et al. (2011) argue, based on a solids mass balance, that the infilling over the

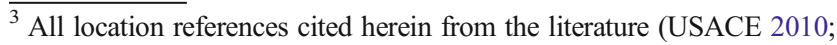
Iannuzzi et al. 2002) have been converted to the RI/FS river mile coordinate system. In USACE coordinates, the navigation channel ends at RM 15.4.

${ }^{4}$ The extent and timing of the upper LPR dredging events in Fig. 2 is based on a review of bathymetric information and channel history. The extent of the 1974 and 1976 events are based on pre- and postdredging bathymetric surveys for a single, phased dredging project. The 1973 event is estimated based on aerial photography, which indicates a channel realignment during highway construction near RM 14 in the early 1970 s. These estimates are used in place of the upriver dredging reported by Iannuzzi et al. (2002) and USACE (2010) (RM 9-10.2 in USACE river miles, about RM 8.7-9.9 in RI/FS river miles).
} 
Fig. 1 Lower Passaic River study area and surrounding region
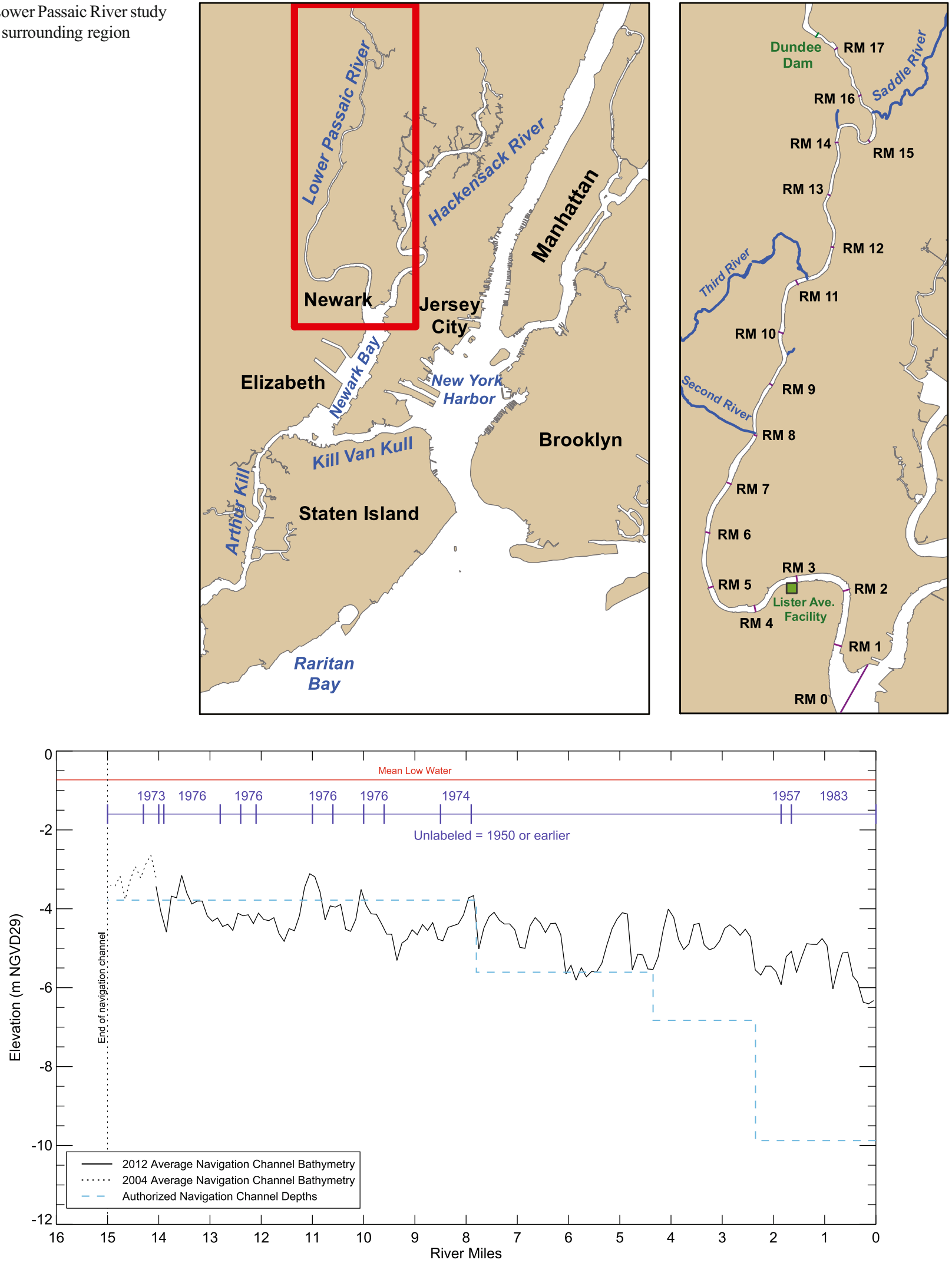

Fig. 2 Mean LPR navigation channel bathymetry based on a 2012 multibeam survey (augmented by a 2004 survey as needed), with authorized navigation channel depths and the approximate year of last channel

review of bathymetric maps; figure is adapted from MPI (2007)]. Smaller, more recent dredging events associated with shipping berth maintenance (see USACE 2010) or remedial actions in the Phase I removal area (2012) and the RM 10.9 removal area (2013) are not shown 
past 60 years is roughly equal to the total solids loading to the LPR, indicating a historical trapping efficiency near $100 \%$. Historical deposition rates as high as 10 to $12 \mathrm{~cm} /$ year in the lower reaches have been inferred from geochronology by past investigators (Huntley et al. 1995; Gillis et al. 1995; Erickson et al. 2007), and more recent coring efforts indicate that historical sedimentation rates in the 1- to $10-\mathrm{cm} /$ year range are common throughout the lower 7 miles of the LPR (discussed below; also consistent with bathymetric differences in Fig. 2). Because the infilling coincided with a period of heavy industrial activity, contaminants were distributed and trapped throughout the LPR. In addition to the channel infilling evident in Fig. 2, side scan sonar, sediment texture, and HOC concentration patterns within the LPR indicate that historically favorable HOC trapping environments existed in much of the river downstream of RM 8 , to a much lesser but still significant extent from RM 8 to RM 14 (as suggested by discrete silt deposits with elevated HOC concentrations, mainly outside the navigation channel), and only for isolated pockets upstream of RM 14 (side scan sonar and grain size data indicate primarily sand and gravel). The contaminant dynamics of the LPR have no doubt evolved over time due to human activity across the region (e.g., source control efforts, sediment remediation, and navigation channel dredging), natural recovery processes (e.g., burial, horizontal/ vertical sediment redistribution), and changing hydrodynamic and sediment transport dynamics as the estuary shoals to reestablish a new geomorphological quasi-equilibrium (see Chant et al. 2011). Although we focus on 2,3,7,8-TCDD, it serves as a tracer to identify processes relevant to other HOCs.

The discussion that follows begins with an overview of the 2,3,7,8-TCDD source and past studies supporting its historical dominance, since this assumption is a prerequisite for the ensuing interpretations of contaminant patterns. A brief summary of the major sediment datasets and their treatment herein are then provided in "Materials and Methods." The "Results and Discussion" presents metrics characterizing the spatial distribution of sediment 2,3,7,8-TCDD in the estuary, and considers its consistency with a single dominant source and the implied suitability of 2,3,7,8-TCDD as a "tracer of opportunity." We then introduce a conceptual framework for interpreting the longitudinal 2,3,7,8-TCDD mass distribution pattern in terms of the net longitudinal flux of the tracer, building off of Jay et al. (1997). HOC fate and transport topics are covered in the following order: (1) upstream transport, (2) downstream transport, and (3) recovery of surface sediments; although some overlap occurs by necessity. Lastly, major insights gained and the general utility of the approach used to infer transport dynamics are considered in "Summary and Conclusions."

\section{The 2,3,7,8-TCDD Source}

The Lister Avenue site is situated along the southern shore of the LPR, approximately 3.1 miles upstream of where the LPR mouth meets Newark Bay (Fig. 1). Between approximately 1948 and 1969, 2,4,5-trichlorophenol and 2,4,5trichlorophenoxyacetic acid $(2,4,5-\mathrm{T})$ were manufactured at the site in the production of herbicides and the military defoliant Agent Orange (Chaky 2003; Lilienfeld and Gallo 1989). Over this period, approximately 7-11 million $\mathrm{kg}$ of 2,4,5-T were produced (Worthington 1983; Silbergeld et al. 1993), representing 4-7 \% of the total US output of 2,4,5-T between 1948 and 1969 (Chaky 2003).

One of the byproducts of the 2,4,5-trichlorophenol manufacturing process is 2,3,7,8-TCDD (Kearney et al. 1973; Hay 1982), which has been the subject of much study due to its potential toxicological effects on humans (Lilienfeld and Gallo 1989). Concentrations of up to $50 \mathrm{mg} / \mathrm{kg}$ have been measured in Agent Orange product samples (National Academy of Sciences 1974); these levels are consistent with 2,3,7,8-TCDD concentrations measured in soils from the Lister Avenue site (Belton et al. 1985). The US Environmental Protection Agency (USEPA) added the Lister Avenue site to the Superfund NPL in September 1984 because of this 2,3,7,8-TCDD contamination, and the site underwent several remedial actions under New Jersey Department of Environmental Protection and USEPA oversight between 1984 and 2004 (USEPA 2008; TSI 2008). In addition to upland remedial efforts, several studies have been initiated in the Passaic River, Newark Bay, and their environs. An RI/ FS was initiated for the lower 6 miles of the LPR in 1994, and for Newark Bay in 2004, including portions of the Hackensack River, Arthur Kill, and Kill Van Kull. Also in 2004, a joint Superfund-Water Resources Development Act study of the entire LPR was initiated. Most recently in 2008, Occidental Chemical Corporation and Tierra Solutions Inc. (TSI) agreed to remove approximately $150,000 \mathrm{~m}^{3}$ of the most highly dioxin-contaminated sediments from the LPR in the immediate vicinity of the Lister Avenue site (Fig. 3), including a Phase I removal area along the site's shoreline (approximately $30,000 \mathrm{~m}^{3}$ ) and an adjacent Phase II removal area (approximately $120,000 \mathrm{~m}^{3}$ ). Sediment cores collected in 2009 and 2011 from within the Phase I removal area detected 2,3,7,8TCDD concentrations as high as $35 \mathrm{mg} / \mathrm{kg}$, and dredging of this area was completed in the summer of 2012 (see Fig. 3 for a delineation of the Phase I and Phase II removal areas).

Several investigators have concluded that the Lister Avenue site was the dominant 2,3,7,8-TCDD source to the LPR and its environs. Bopp et al. (1991) reached this conclusion (also for 2,3,7,8-tetrachlorodibenzo-p-furan [2,3,7,8$\mathrm{TCDF}]$ and DDT) on the basis of age-dated sediment cores collected near the site and in the surrounding region, noting in particular that: (1) the timing of peak concentration coincides with the production period at the Lister Avenue site; (2) concentrations decline moving away from the site for time horizons in the 1960s and 1980s (also in Bopp et al. 1998); (3) the decline between the 1960s and 1980s is consistent with the 


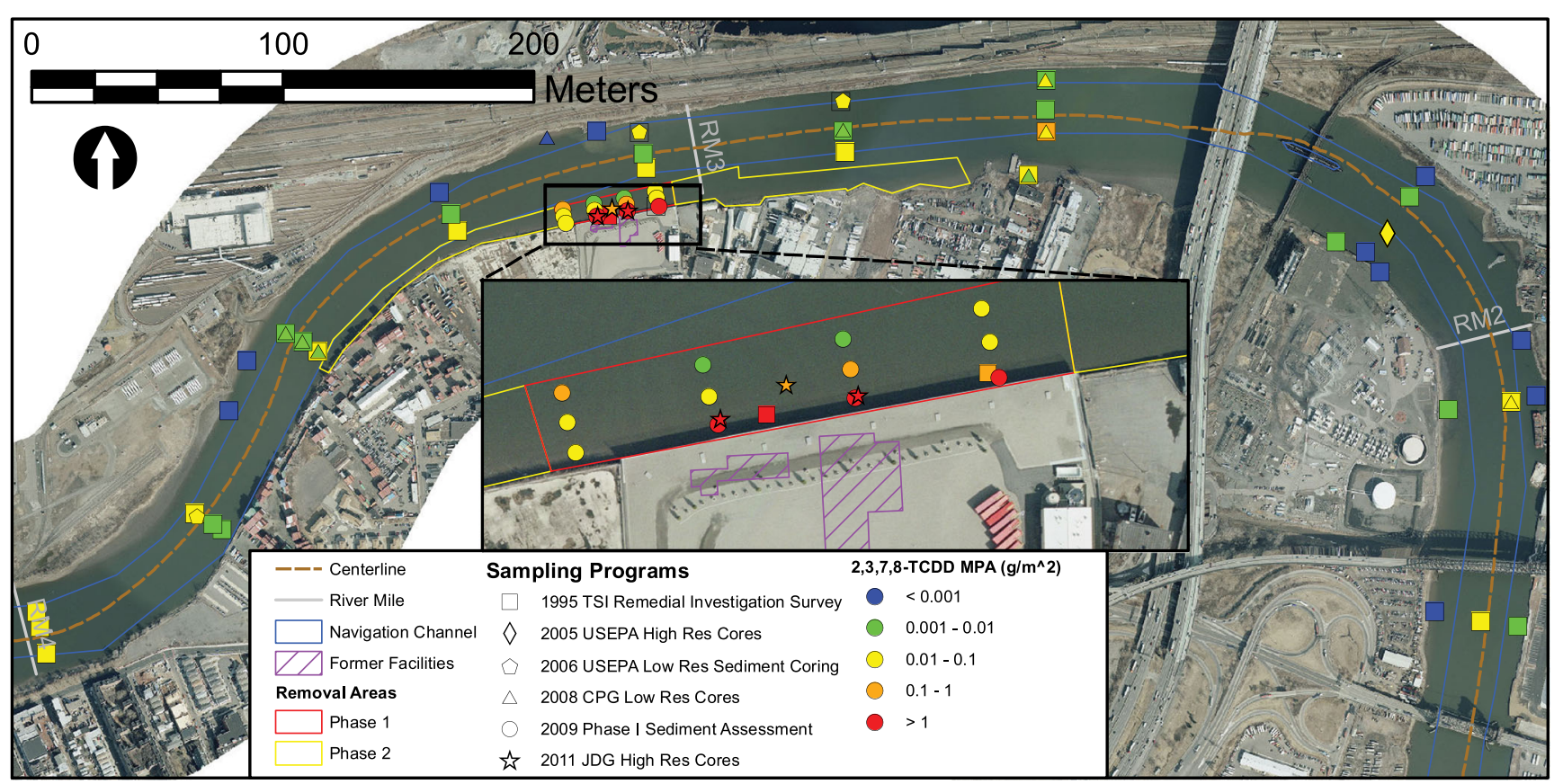

Fig. 3 Near-field distribution of estimated 2,3,7,8-TCDD mass-per-area; inset shows a close-up of the Phase I removal area adjacent to the Lister Avenue site. The coring datasets shown are provided in the legend

Lister Avenue site production ceasing in 1969; and (4) high concentrations were found in soil samples collected from the Lister Avenue site. Similar regional spatial and temporal patterns were noted by Chaky (2003) for the 1960s and 1995 periods using age-dated cores from Newark Bay and throughout the New York/New Jersey (NY/NJ) Harbor Estuary. Chaky (2003) further noted a similar spatial pattern in the ratio of 2,3,7,8-TCDD to total TCDD, a "fingerprint" suggested by Tong et al. (1990) and Bopp (1992), which is known to be characteristically high for waste associated with the 2,4,5-T manufacturing process used at the Lister Avenue site. Soil samples collected in the vicinity of the Lister Avenue site exhibited ratios in the range of 0.86-0.98 (Umbreit et al. 1986; Wenning et al. 1993a), and LPR sediments typically exhibit a ratio above 0.6 at the 2,3,7,8-TCDD peak depth [Chaky (2003) measured 0.71 and 0.86 in Newark Bay, and more recent LPR data are discussed below]. By contrast, wastewater and atmospheric sources exhibit a much lower ratio on the order of 0.06 or less (Chaky 2003). Chaky (2003) concluded that the ratio of 2,3,7,8-TCDD to total TCDD can be considered a fingerprint, which distinguishes TCDD contamination originating from the Lister Avenue site from the major background or non-point sources to the LPR. Using data from the 1990s, Hansen (2002) concluded via a principal component analysis (PCA) and cluster analysis that the Lister Avenue site was the most dominant single source of 2,3,7,8-TCDD to the NY/NJ Harbor Estuary. Most recently, the dominant source hypothesis was assumed in the work of Chant et al. (2011), based on the consistency in timing between Lister Avenue site production and the 2,3,7,8-TCDD peak concentration observed in five high resolution cores spaced along the LPR from RM 1.4 up to RM 12.6. Chant et al. (2011) conclude that the upstream (landward) sediment transport mechanisms that dominate during low flow conditions explain, in part, Lister Avenue site contamination reaching RM 12.6, especially given two conditions that would have favored enhanced upstream transport at the time of the discharges. First, upstream salt front penetration during low flows would have been greater before widespread infilling of the navigation channel occurred. Second, Lister Avenue site production years coincided with a drought period from 1962 to 1966, during which low flow conditions and upstream transport would have been more common.

The dominance of the Lister Avenue site source was challenged ${ }^{5}$ by a series of papers analyzing 1990s' datasets with statistical pattern recognition techniques [e.g., PCA, polytropic vector analysis (PVA), and cluster analysis] to demonstrate that a multitude of sources contributed to the various polychlorinated dibenzodioxin and polychlorinated dibenzofuran (PCDD/PCDF) congeners in the LPR, Newark Bay, and surrounding areas, including industrial discharges, municipal sewage and wastewater, waste incineration, combustion engines, coal-fired power plants, sources associated with polychlorinated biphenyls, CSOs, etc. (Wenning et al. 1992, 1993a, b; Ehrlich et al. 1994; Huntley et al. 1997, 1998). Wenning et al. (1993a) further indicate that the PCDD/PCDF distribution in soils on the Lister Avenue site and sediments

\footnotetext{
$\overline{5}$ In addition, the conclusions of Bopp et al. (1991) were debated in follow-up comments by Bedbury (1992), Wenning et al. (1992), and Bopp (1992).
} 
adjacent to the site are dissimilar to sediments elsewhere in the estuary. However, these findings do not disprove a dominant 2,3,7,8-TCDD source because 2,3,7,8-TCDD is generally a small percentage of the overall PCDD/PCDF mass (Bopp et al. 1991; Hansen 2002). For example, Bopp et al. (1991) notes that octachlorodibenzodioxin (OCDD) is by far the more abundant dioxin in Newark Bay and Bopp et al. (1998) suggest an atmospheric signal based on regional patterns. Rather, Tong et al. (1990), Bopp (1992), and Chaky (2003) noted that the Lister Avenue site source was characterized by a high fraction of 2,3,7,8-TCDD relative to the total TCDD concentration, and hence the characteristic fingerprint used by Chaky (2003).

Lastly, it is noted that two of the above studies (Huntley et al. 1998; Hansen 2002) suggested that 2,3,7,8-TCDD was contributed from a source located approximately 11 miles upstream of the LPR mouth on the Third River. However, this presumption is based on a single sample point having congener concentrations an order of magnitude lower than the downstream sediments and provides no indication of a substantive impact on the 2,3,7,8-TCDD concentrations in the river. Moreover, as discussed below in the context of larger and more recent datasets, 2,3,7,8-TCDD concentrations at or above this section of the river are generally consistent with the Lister Avenue site source signature as well as upstream transport processes.

Additional support for the dominance of the Lister Avenue site 2,3,7,8-TCDD loading is presented in "Results and Discussion" in the context of using $2,3,7,8$-TCDD as a tracer of opportunity for the present study.

\section{Materials and Methods}

\section{Datasets}

A rich dataset ${ }^{6}$ has been, and continues to be, collected in the LPR and adjacent waterways under the RI/FS process, aimed at characterizing the sediment bed's physical properties and concentrations of a wide range of contaminants. This paper focuses on sediment cores collected as part of the following programs: 1995 TSI Remedial Investigation Survey (90 cores), 2005 USEPA High Resolution Coring Program (6 cores), 2006 USEPA Low Resolution Sediment Coring (10 cores), 2008 LPR Cooperating Parties Group (CPG) Low Resolution Coring (LRC) Survey (107 cores), 2009 TSI Phase I Sediment Assessment (12 cores), 2011 Joint Defense Group (JDG) Passaic River Sediment Sampling (high resolution sampling only; 3 cores), 2011 LPR CPG RM 10.9 Sediment Deposit Characterization (54 cores), 2012 TSI Focused Sediment Investigation (FSI; 6 cores), and, in Newark Bay,

\footnotetext{
${ }^{6}$ As of November 2013, most but not all of the datasets used herein are publicly accessible via the Passaic Digital Library at http://passaic. sharepointspace.com/SitePages/Home.aspx.
}

the 2005 Phase I and 2007 Phase II Remedial Investigation Survey $\left(98\right.$ cores $\left.^{7}\right)$. In the characterization of surface sediments, surface grabs (132 locations; 0-15 cm) from the 2009/2010 Remedial Investigation Field Sampling Plan 2 Benthic Sediment Sampling Program and short-cores (87 locations; 0-15 cm surface slice) from the 2012 CPG Supplemental Sampling Program are also included, along with some additional smaller datasets from the year 2000 or later $^{8}$ (collectively, the surface sediment data are herein referred to as a the "post2000 dataset"). In addition, we draw upon Acoustic Doppler Current Profiler (ADCP) and conductivity, temperature, and depth (CTD) sensor measurements from deployments of five moorings along the LPR from the 2009/2010 CPG physical water column monitoring program but do not incorporate the associated turbidity measurements. Several other data collection efforts were ongoing at the time of manuscript preparation, aimed at characterizing water column contaminant fluxes and filling data gaps in sediment bed concentrations. Analysis of these additional data may in the future reveal further insights.

\section{Summary of Sediment Data Treatment}

The study analyzes large-scale trends in the LPR and Newark Bay in the measured peak and surface sediment 2,3,7,8TCDD concentrations and the measured ratio of 2,3,7,8TCDD to total TCDD. Nondetect concentrations were set equal to one half the detection limit, but the corresponding ratio of 2,3,7,8-TCDD to total TCDD was excluded from consideration in these cases. Organic carbon (OC) normalization of the 2,3,7,8-TCDD concentrations is employed when plotting spatial trends to reduce the variability associated with spatial gradients in sediment OC content within the system. In order to highlight large-scale longitudinal concentration trends and to facilitate discussion, sediment samples have in some figures been grouped into approximately 2 -mile bins ${ }^{9}$ and averaged. In some cases, bins were further split between areas inside and outside the federal navigation channel. Sediment cores from within the Phase I removal area immediately

\footnotetext{
${ }^{7} 55$ cores from the Newark Bay datasets are used in subsequent figures, reflecting the longitudinal extent of analyses herein (RM -5) as well as the filtering of cores without evidence of reaching the 1940 horizon (per evaluation of TSI 2011b) and Phase I cores with a co-located Phase II core indicating a deeper inventory. Such filtering was not conducted for the other core data sets.

${ }^{8}$ Additional datasets used to characterize surface sediments $(0-15 \mathrm{~cm})$ include: 2000 TSI Spring RI-ESP Sampling Program, 2000 Toxicity Identification Study, 2007-2008 USEPA Sediment Sampling Program, and the 2007 Dundee Lake Core Sampling. Surface grabs from all datasets were used when available.

${ }^{9}$ Two-mile bins are used within the LPR from RM 0 to RM 14. RM 14 17.4 is treated as a single bin due to lower data density. A single bin within the UPR is shown (RM 17.4-20) to provide context for upstream influence. Two longitudinal bins of approximately 2.5 miles each are considered in Newark Bay. The area beyond RM -5 (i.e., as defined by extending LPR $\mathrm{RMs}$ ), where the navigation channel branches, is not included; this longitudinal extent is similar to that presented in Chant et al. 2011.
} 
adjacent to the Lister Avenue site are binned separately from other sediment cores collected in this reach. Similarly, sediment core data from the tributaries to the LPR are binned separately to examine potential tributary contributions to 2,3,7,8-TCDD levels in the LPR.

When analyzing the ratio of 2,3,7,8-TCDD to total TCDD, the 1995 TSI RI dataset has been excluded due to data quality concerns, specifically many instances in which the reported ratio exceeds 1 , which by definition is not possible. In contrast, the remainder of the merged core dataset contains few instances ${ }^{10}$ of ratios in excess of 1 , for low concentration samples relative to the overall dataset; presumably, this reflects an improvement in the analytical methods for quantifying 2,3,7,8-TCDD and total TCDD between the mid-1990s and the late-2000s. The 1995 dataset is, however, used in evaluating trends in absolute concentration ${ }^{11}$ and mass per area of 2,3,7,8-TCDD, with the caveat that the analytical method used was likely less precise than in later datasets. The 2012 TSI FSI dataset is also excluded from ratio plots because total TCDD measurements were not available.

Spatial trends in the estimated 2,3,7,8-TCDD mass inventory are also considered. Mass-per-area values were computed from cores as the product of paired dry density and 2,3,7,8-TCDD concentrations, summed over the length of the sediment column, using an average dry density when core-specific values were unavailable. Only "complete cores" as defined by continuous 2,3,7,8-TCDD profiles ( $4 \mathrm{~cm}$ tolerance) were analyzed in this fashion, with the exception of high resolution cores (2005 and 2011) where linear interpolation between measured values was performed in some cases of larger gaps. Estimates of 2,3,7,8TCDD mass inventory were generated using Thiessen polygons with the calculated mass-per-area values, and an analytical framework is introduced in the interpretation of the resulting mass spatial trends; see "Results and Discussion." An alternate approach to generating the mass distribution is also presented, in which separate Thiessen polygons were created for inside the navigation channel and for either side of the channel, to reflect lateral gradients arising from factors such as historical channel infilling and dredging, and the prevalence of discrete silt deposits above RM 8. Although investigation of refinements to the calculation continues (e.g., by interpolating within zones of like physical characteristics, or by including additional data such as recent short-core survey results for cores that appeared to capture

\footnotetext{
${ }^{10}$ A ratio in excess of 1 was noted in four instances in the 2008 CPC LRC dataset and one instance in the 2009 TSI Phase 1 Sediment Assessment dataset. One of the cases occurred at the local peak 2,3,7,8-TCDD concentration depth, but for a very low concentration core relative to the overall merged dataset; see further discussion in "Results and Discussion."

${ }^{11}$ Some caution is also noted with regard to OC normalization of the 1995 TSI RI core dataset due to the unusually high OC measurements, relative to later sampling surveys. Dry weight spatial trends are therefore also presented in "Results and Discussion," when this dataset is employed.
}

the inventory), these refinements are not likely to substantially alter the large-scale longitudinal trend that is the focus of the ensuing discussion.

In addition to 2,3,7,8-TCDD, trends in estimated net sedimentation rates are also considered. For the 1995 core dataset, the sedimentation rate values reported by Erickson et al. (2007) were adopted, which were derived from core dating based on a combination of cesium-137 (Cs-137) profiles (associating peak and first onset Cs-137 levels with 1963 and 1954, respectively) and lead-210 (Pb-210) profiles (fitting the excess $\mathrm{Pb}-210$ profile to a one-dimensional advectiondecay equation). As discussed in Erickson et al. (2007), the "preferred" rate for each location was selected based on the relative quality of the Cs-137 and $\mathrm{Pb}-210$ profiles. For the 2008 CPG LRC dataset, a similar methodology was applied by the original investigators (AECOM, unpublished), and results were reviewed by the present authors. For the 2005 USEPA high resolution cores, 2011 RM 10.9 cores, 2011 JDG high resolution cores, and 2012 TSI FSI cores, only Cs-137 profiles were considered (if deemed of sufficient quality).

Lastly, trends in the surficial sediment grain size distribution (GSD) are considered, in particular the fraction of fine sediments. Because the reported sieve sizes differed among the studies that included GSD data, a mixed query was used to define the fraction of fine sediments. When available, the reported fraction passing the $63-\mu \mathrm{m}$ sieve size was used (number 230); in other cases, 74- $\mu \mathrm{m}$ sieve (number 200) data were used.

\section{Results and Discussion}

\section{2,3,7,8-TCDD as a Tracer of Opportunity}

The use of 2,3,7,8-TCDD as a "tracer of opportunity" is predicated on the assumption that the sediment 2,3,7,8TCDD distribution reflects mainly the influence of a single dominant historical source, from which contaminant was dispersed throughout the estuary over time. The data support for this assumption is summarized below, along with an overview of how the tracer is used in the remainder of the study.

The regional dominance of the Lister Avenue site source of 2,3,7,8-TCDD is inferred from the prevailing spatial patterns in the LPR, its tributaries, and Newark Bay. Spatial patterns in sediment concentration data are commonly used to identify contaminant sources to a system because the highest concentrations typically occur at the source location and decline with distance from the source. This approach was used by Bopp et al. (1991, 1998) and Chaky (2003) to originally suggest that the Lister Avenue site was the regional source of 2,3,7,8TCDD to the Newark Bay complex, based on concentrations associated with specific time horizons (as identified by geochronological markers). Another prominent example is 
provided by Connolly and Glaser (2002) in the Southern California Bight, where an ocean outfall was identified as the dominant source of regional dichlorodiphenyl dichloroethylene contamination based on observations of monotonically declining concentrations moving away from the outfall. A combination of concentration and estimated mass inventory patterns are herein used to infer the dominance of the Lister Avenue site source.

Cores collected in the vicinity of the Lister Avenue site indicate a spatial distribution of 2,3,7,8-TCDD inventory (Fig. 3) that is consistent with the near-field accumulation of contaminant from a concentrated source. The highest 2,3,7,8TCDD mass-per-area estimates are within the Phase I removal area immediately adjacent to the Lister Avenue site (red/orange symbols in Fig. 3, see inset), which also includes the highest 2,3,7,8-TCDD concentration measured throughout the LPR $(35 \mathrm{mg} / \mathrm{kg})$. Approximately $30 \mathrm{~m}$ offshore of these cores, the mass-per-area estimates are lower by a factor of $10-1,000$ (yellow/green symbols), and continue to generally decline moving laterally across the river. Mass-per-area values immediately upstream and downstream of the Lister Avenue site are similar to or lower than those found within the Phase I removal area. These mass accumulation patterns are generally consistent with the settling and trapping of 2,3,7,8-TCDD within depositional environments near the Lister Avenue site, ${ }^{12}$ with spatial gradients arising from longitudinal and lateral mixing of the initial discharge plume and subsequent sediment redistribution by tidal processes and river flow events. The suspended solids flux calculations by Chant et al. (2011; using ADCP and acoustic backscatter measurements collected in the same reach shown in Fig. 3, near RM 3) demonstrate the periodic resuspension, transport, and redeposition of a thin layer of sediments over the course of the tidal cycle, with the direction and magnitude of the net flux depending on the relative strengths of the freshwater flow, tidal currents, and gravitational circulation. Over time and most intensely during high flow events, these factors would tend to disperse sediments longitudinally and laterally, causing fine sediments and the associated $2,3,7,8$-TCDD to preferentially accumulate in areas of lower shear stress. ${ }^{13}$ Sediment redistribution processes would also induce a net contaminant flux away from the original discharge site, which would be expected to favor upstream transport during low flows and downstream transport during high flows (discussed in subsequent sections).

\footnotetext{
$\overline{12}$ For example, the three 2011 high resolution cores collected adjacent to the Lister Ave site show 2,3,7,8-TCDD concentration peaks that are buried at about 1.5-2.5 m, and which coincide with the production period at Lister Ave; see "Recovery" section for core profiles.

${ }^{13}$ Several features in Fig. 3 are consistent with expected differences in shear stress and historical depositional environment; for example, massper-area estimates are higher on the inner bend upstream of the site relative to the outer bend (approximately RM 3.2-3.5).
}

Zooming out to a larger scale, the longitudinal distribution of core-maximum 2,3,7,8-TCDD concentrations ${ }^{14}$ across the LPR and Newark Bay (Fig. 4) is consistent with the influence of this concentrated source. The mean core-maximum 2,3,7,8-TCDD concentrations are highest in the region encompassing the Lister Avenue site (RM 2-4), particularly within the Phase I removal area immediately adjacent to the site where the mean peak concentration (red point) is more than 100 times greater than in remaining areas in the RM 2-4 bin. The mean peak concentrations are lower moving away from the RM 2 to RM 4 bin, but are fairly well distributed throughout the lower 14 miles of the LPR (within a factor of 3-6 of the RM 2-4 bin, depending on whether or not OC normalization is used). Moving across Newark Bay, the concentrations drop dramatically; the mean peak concentration in the lower Newark Bay bin is approximately 25-89 times lower than the mean within the RM 2-4 reach and three to four orders of magnitude lower than the mean within the Phase I removal area. Likewise, moving upstream of RM 14, peak concentrations drop on average by two orders of magnitude, reaching levels similar to those above Dundee Dam. The large-scale pattern ${ }^{15}$ is consistent with the Lister Avenue site being the predominant source of the historical 2,3,7,8-TCDD contamination in the region; 2,3,7,8-TCDD levels from sources upstream of the Dundee Dam and LPR tributaries (green markers in Fig. 4) are too low to account for the 2,3,7,8-TCDD contamination observed throughout the LPR, and the presence of elevated concentrations throughout the lower 14 miles of the LPR is consistent with estuarine transport processes (discussed in subsequent sections).

The notion that the observed concentration distribution reflects the mixing of 2,3,7,8-TCDD from a single dominant source is further supported by the spatial distribution of the ratio of 2,3,7,8-TCDD to total TCDD at the depth of maximum 2,3,7,8-TCDD concentration (Fig. 5a), and we note that age dating of sediment cores collected immediately adjacent to the Lister Avenue site supports the use of this fingerprint (not

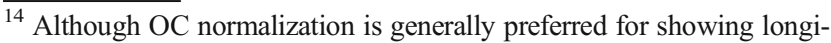
tudinal trends due to observed OC gradients within the LPR/Newark Bay, Fig. 4 includes a dry weight spatial because of data quality concerns over the unusually high OC values in the 1995 dataset. The longitudinal trend is similar on a dry weight basis, although the mean in the RM 2-4 bin becomes somewhat more elevated relative to neighboring bins and the RM 12 to RM 14 bin is lower.

${ }^{15}$ Two additional longitudinal features are noted, which are not captured by the bins used in Fig. 4. First, the overall decline in mean peak concentration moving across Newark Bay is somewhat milder if only cores outside the navigation channel are considered (the lower Newark Bay bin mean is then approximately 19 to 64 times lower than the RM 2 to RM 4 mean); as discussed later, extensive navigation channel dredging below RM 2 occurred subsequent to the Lister Avenue site production period. Second, the most elevated peak concentrations within the RM 12 to RM 14 bin occur in cores near or below RM 13, indicating that the drop off in peak concentrations begins somewhat further downstream than RM 14 (mean surface concentrations are also lower in this bin; see "Recovery").
} 


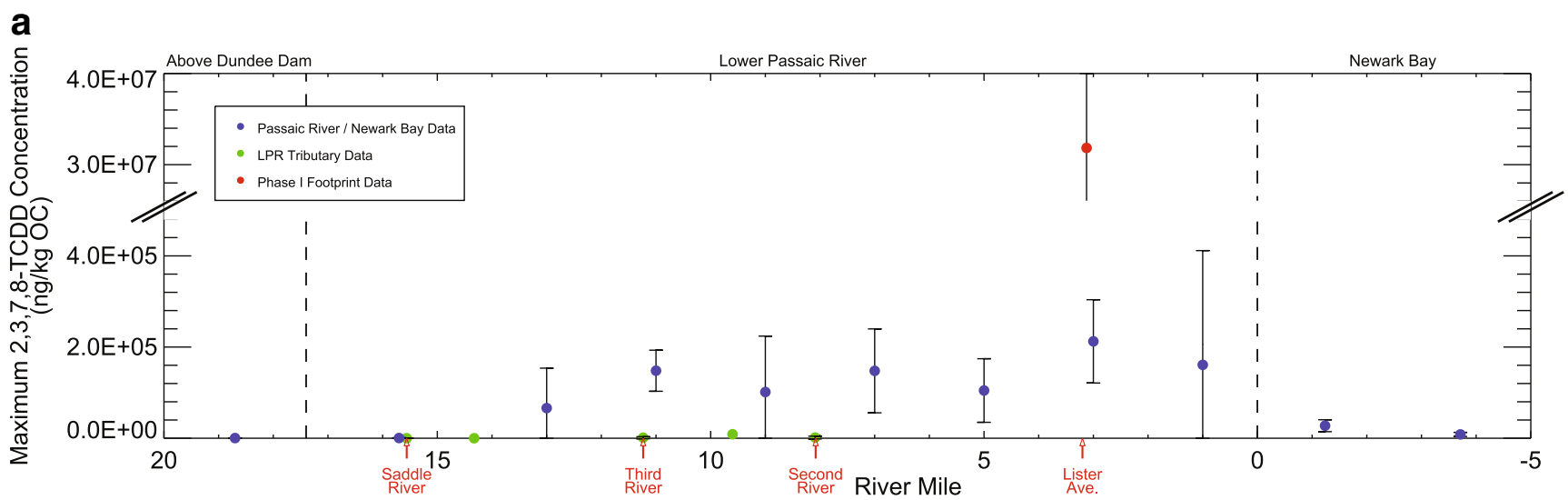

b

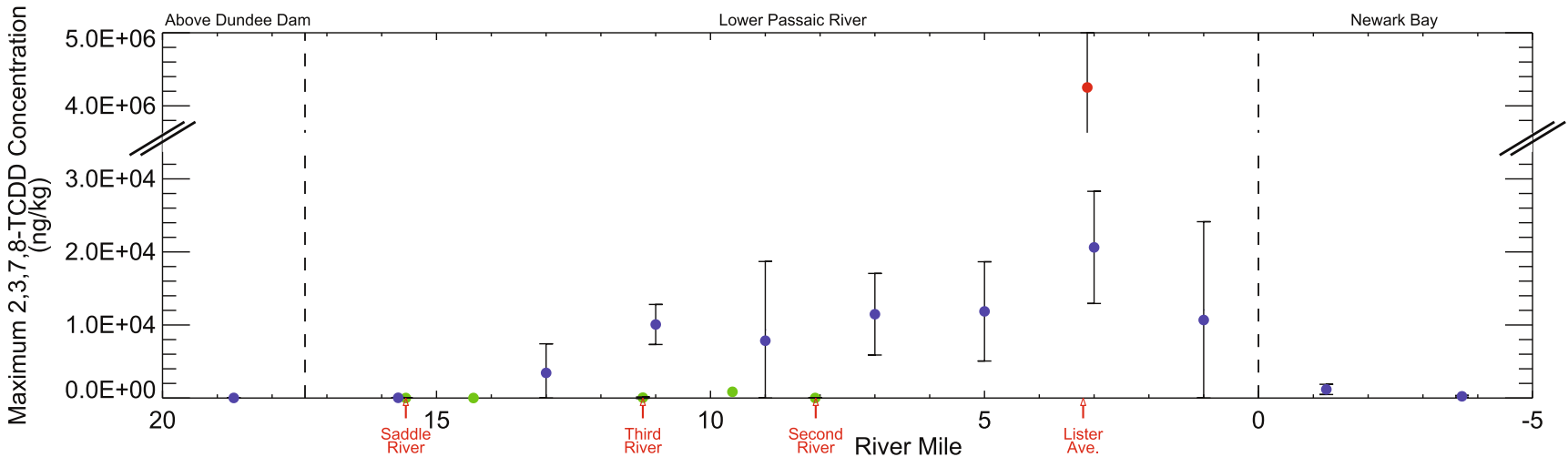

Fig. 4 Longitudinal distribution of peak 2,3,7,8-TCDD concentrations along the LPR and Newark Bay (mean +2 SE; note the discontinuous vertical scale): a OC-normalized basis b dry-weight basis. 2,3,7,8-TCDD peaks are identified on a dry-weight basis in both panels for consistency.
Figure considers all coring data listed in "Datasets," but the 2012 TSI FSI dataset and several additional cores are excluded from the top panel because OC data were not available at the 2,3,7,8-TCDD peak

concentration. Moreover, it is noted that 2,3,7,8-TCDD peak concentrations above approximately 100 and $1,000 \mathrm{ng} / \mathrm{kg}$ are mainly associated with $2,3,7,8$-TCDD to total TCDD ratios in excess of about 0.6 and 0.7 , respectively (Fig. 5b). Thus, elevated peak concentrations throughout the system are typically associated with the fingerprint ratio that has been attributed to the Lister Avenue site. ${ }^{18}$ Although the 2,3,7,8-TCDD to total TCDD ratio patterns do not preclude the influence of other 2,3,7,8-TCDD sources with a similar signature, it is noted that the dominant source hypothesis is supported by an

\footnotetext{
${ }^{17}$ Figure 5a shows one measurement in the merged core dataset in which a 2,3,7,8-TCDD to total TCDD ratio in excess of 1 was reported at the 2,3,7,8-TCDD peak, which by definition is not possible. This data point corresponds to 2008 CPG LRC Core CLRC-103 collected above Dundee Dam, and is one of the lowest peak concentrations in the merged core dataset (Fig. 5b). Therefore, it does not contradict the notion of a dominant Lister Avenue site source; rather, it is taken as an isolated analytical error for a low concentration sample.

${ }^{18}$ The variability in 2,3,7,8-TCDD to total TCDD ratios is greater when samples not at the local peak concentration are also considered, but support the association of elevated 2,3,7,8-TCDD concentrations to ratios well above background sources. Mean ratios in surface sediments are presented in "Recovery".
} 

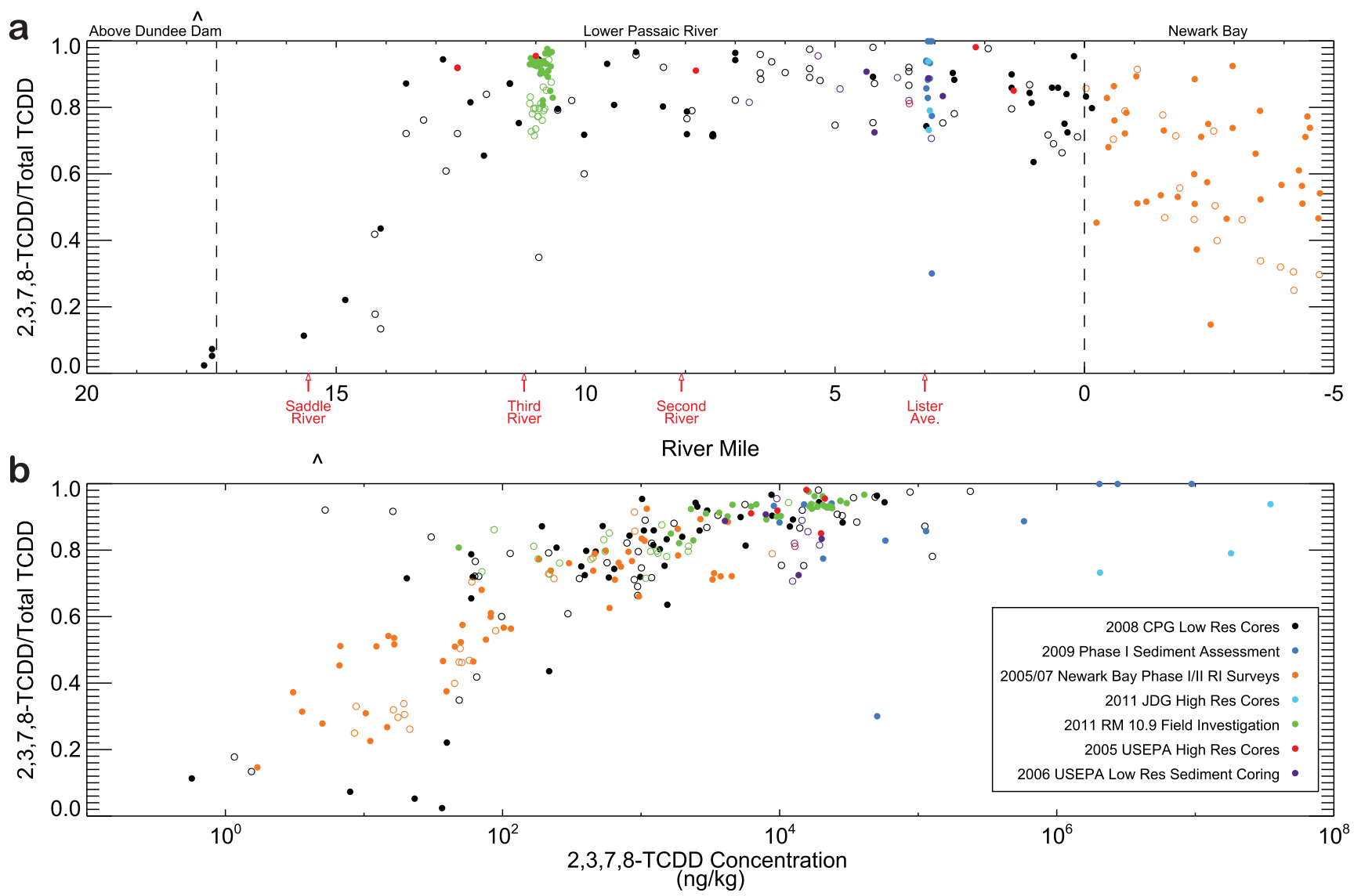

Fig. 5 a Longitudinal distribution of the ratio of 2,3,7,8-TCDD to total TCDD at the local depth of maximum 2,3,7,8-TCDD concentration. b 2,3,7,8-TCDD to total TCDD ratio at the local depth of maximum 2,3,7,8 concentration, plotted as a function of the maximum concentration. Open and closed symbols indicate samples collected inside and outside the navigation channel, respectively, and $\operatorname{caret}\left({ }^{\wedge}\right)$ denotes a reported ratio above 1 . The coring datasets used are provided in the legend additional fingerprint of the Lister Avenue site discharges that has been identified within the LPR (not shown; manuscript in preparation).

Lastly, the dominance of the Lister Ave source is indicated by the longitudinal distribution of estimated 2,3,7,8-TCDD mass inventory (Fig. 6a, based on interpolation ${ }^{19}$ ). The mass estimate for the RM 2-4 bin is highest, declining upstream and downstream, particularly when expressed on a mass-per-area basis (Fig. 6b). Although the mass distribution is certainly influenced by the long-term trapping behavior of the estuary and navigational channel dredging (see "Upstream Transport" and "Downstream Transport"), when combined with the patterns in peak concentration and the dioxin fingerprint, the weight of evidence indicates that the Lister Avenue site is the dominant

\footnotetext{
${ }^{19}$ Thiessen polygons were here delineated for mass-per-area estimates from cores with continuous 2,3,7,8-TCDD profiles; see "Summary of Sediment Data Treatment." Mass removals associated with subsequent remedial dredging of the Phase I removal area (2012) and the RM 10.9 sediment deposit (2013) are not accounted for, given the focus on longterm fate and transport patterns. Likewise, maintenance dredging of shipping berths and the navigation channel in Newark Bay is not accounted for.
}

historical source of 2,3,7,8-TCDD contamination throughout the LPR and Newark Bay.

Based on the above observations, 2,3,7,8-TCDD is below employed as a "tracer of opportunity" to gain insight into fate and transport processes within the estuary, and the discussion is organized into two basic applications of the tracer. First, the long-term longitudinal net fluxes of 2,3,7,8-TCDD are evaluated, which are interpreted within the context of prevailing HOC transport mechanisms within the estuary (see "Net 2,3,7,8-TCDD Flux Within the Estuary," "Upstream Transport," and "Downstream Transport"). Second, 2,3,7,8TCDD is used to illustrate natural recovery since the Lister Avenue site discharge ceased (see "Recovery of Surface Sediments Following Source Control”).

Net 2,3,7,8-TCDD Flux Within the Estuary

As detailed in the review of estuarine scalar flux estimation techniques by Jay et al. (1997) (see also Schubel and Carter 1984; Yu et al. 2012), quantifying net transport in estuaries by 

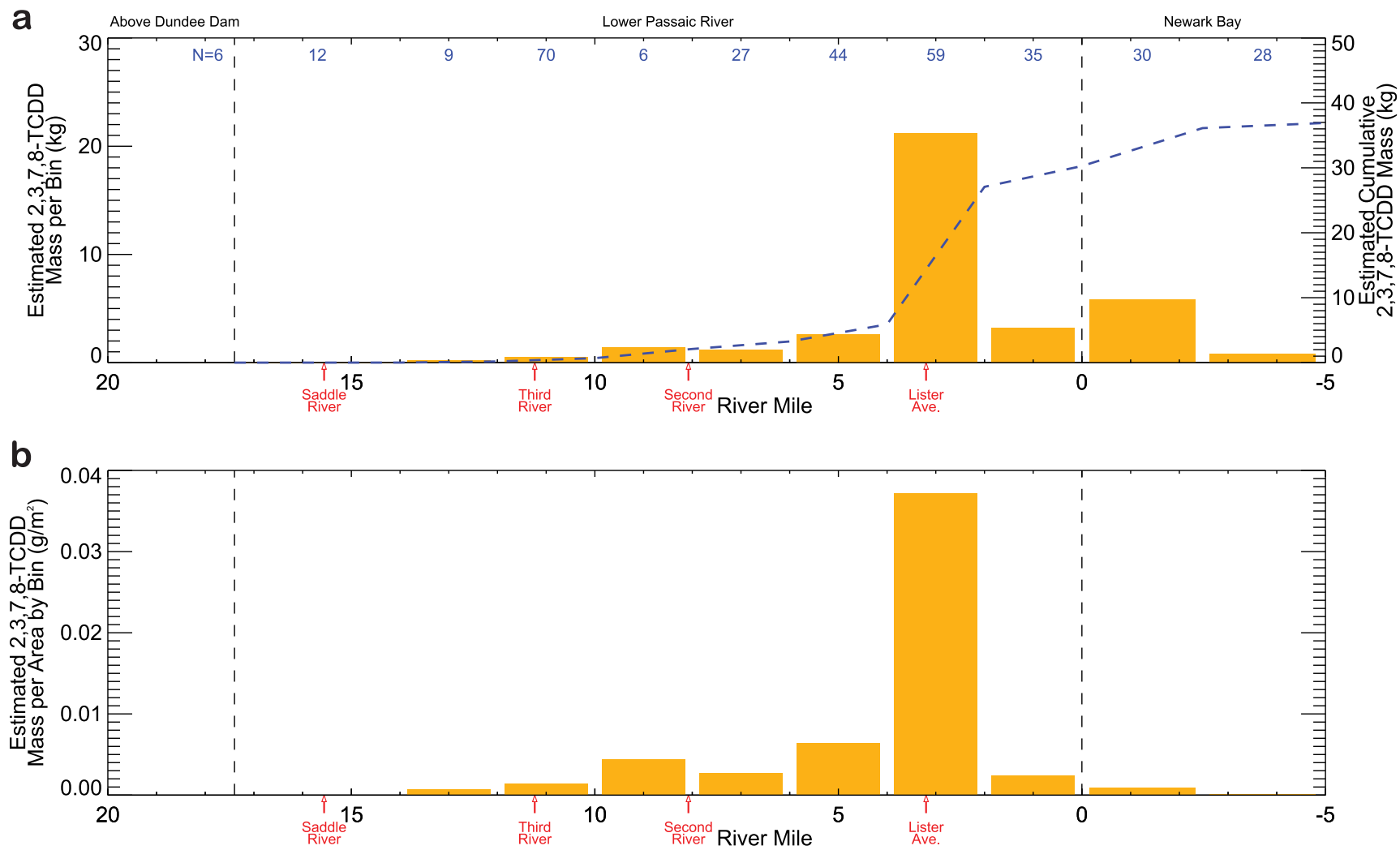

Fig. 6 a Longitudinal distribution of the estimated 2,3,7,8-TCDD mass inventory (using Thiessen polygons per description in "Summary of Data Treatment" applied to the coring surveys listed in "Datasets"; the number of cores in each bin is shown). b The longitudinal distribution of 2,3,7,8TCDD mass-per-area implied by the mass interpolation in Fig. 6a

The rich sediment 2,3,7,8-TCDD dataset available in the study area allows us to circumvent some of these difficulties by using an "indirect method" (Jay et al. 1997) to assess longterm net 2,3,7,8-TCDD fluxes along the LPR. In particular, the cumulative mass distribution line in Fig. 6a (blue dashed line) can qualitatively be understood using the following expression, which we derived by taking the general water column mass conservation equation proposed for an idealized micro-tidal estuary by Jay et al. (1997), pairing it with an analogous expression for the sediment bed, and solving to yield:

$$
\begin{gathered}
M_{\text {bed }}\left(t^{\prime}, x_{1}, x_{2}\right) \approx \int_{0}^{t^{\prime}}\left\{-\left[\int U C_{\mathrm{wc}} \mathrm{d} A\right]_{x_{1}}^{x_{2}}+\int B_{\text {air }} \mathrm{d} S+\right. \\
\left.\int_{x_{1}}^{x_{2}}\left[\dot{m}_{\mathrm{LA}} \delta\left(x-x_{\mathrm{LA}}\right)-\ddot{m}_{\mathrm{D}}\right] \mathrm{d} x\right\} \mathrm{d} t
\end{gathered}
$$

Here, $M_{\mathrm{bed}}$ is the sediment bed 2,3,7,8-TCDD mass inventory that has accumulated within the longitudinal interval $x_{1}$ to $x_{2}$ over a long time interval $0<t<t^{\prime}\left(t^{\prime}>>\right.$ tidal period $\left.T\right)$; $C_{\mathrm{wc}}(t, x, y, z)$ is the total water column $2,3,7,8$-TCDD concentration $\left(M / L^{3}\right) ; U(t, x, y, z)$ is the longitudinal velocity $(L / T)$; $B_{\text {air }}(t, x, y)$ is the mass flux $\left(M / L^{2} T\right)$ across the air-water interface; $A(t, x)$ is the cross-sectional area of the water column [i.e., $\left.\mathrm{d} A=\mathrm{d} y \mathrm{~d} z ;\left(L^{2}\right)\right] ; S\left(x_{1}, x_{2}\right)$ is the surface area of the bed and 
water surface between $\mathrm{x}_{1}$ and $\mathrm{x}_{2} ; \ddot{m}_{\mathrm{D}}(t, x)$ is the mass removal due to dredging events expressed as a rate per unit length $(M /$ $L T) ; \dot{m}_{\mathrm{LA}}(t)$ is the historical Lister Avenue site 2,3,7,8-TCDD loading $(M / T)$ to the LPR expressed as a time-variable rate; and $\delta(x)$ is the Dirac delta function (units of $1 / \mathrm{L}$ ) used here to specify the Lister Ave site loading at $x=x_{\mathrm{LA}}$ only. Equation 1 ignores all loss terms from the coupled sediment bed and water column system other than dredging and volatilization, since they are expected to be small for the highly persistent 2,3,7,8-TCDD. Equation 1 also assumes that the 2,3,7,8TCDD mass accumulated in the sediment bed far exceeds the mass in the water column, which is valid over long timescales only. Because we only use the equation as a conceptual framework, other details and assumptions adopted in the derivation are omitted for brevity.

Notwithstanding uncertainty associated with core density, spatial variability, and interpolation, the cumulative mass inventory in Fig. 6a (blue dashed line) can be interpreted using Eq. 1 by letting $x_{1}$ be the Dundee Dam (RM 17.4), letting $x_{2}$ be the distance downstream (seaward), and interpreting the interval 0 to $t^{\prime}$ as the period 1948 (first Lister Avenue site production year) through the time of core collection (which here spans the interval 1995-2012 but is weighted toward the later years). The first term on the right-hand side (rhs) of Eq. 1 is then the net advective flux of 2,3,7,8-TCDD to the region upstream of $x_{2}$, integrating over time the combined effect of the complex transport dynamics noted above. The second rhs term is the air exchange (volatilization and atmospheric deposition) over the same period, and is likely negligible relative to the advective term. The last terms are the mass loading associated with the Lister Avenue site source (assumed to be the only significant one per earlier discussion) and the mass sink associated with dredging activities. Thus, Eq. 1 simply states that the mass observed upstream of a particular location $x_{2}$ is the time-integrated net advective flux across $x_{2}$, plus the Lister Ave discharge if $x_{2}>x_{\mathrm{LA}}$, minus any mass removal due to dredging upstream of $x_{2}$. The accuracy of Eq. 1 is somewhat less in Newark Bay because the Hackensack River exchange is unaccounted for, but this is a minor caveat as the equation is employed only as a conceptual framework and we focus mainly on the LPR.

A central goal of the present study is to gain insight into the fate and transport processes controlling the net longitudinal contaminant flux (i.e., first rhs term in Eq. 1), and the influence of dredging on the observed 2,3,7,8-TCDD distribution introduces some additional uncertainty into the interpretation. The onset of the Lister Avenue site production in 1948 coincides approximately with the cessation of most channel dredging upstream of RM 1.9 (Fig. 2), with the exception of several smaller intervals where the navigation channel was partially dredged in the 1970s (these span a combined total of approximately 3 miles upstream of RM 7.9). Below RM 1.9, the potential influence of dredging is by comparison much greater, given that maintenance dredging of the LPR and Newark
Bay navigation channels continued during and after the postLister Avenue discharge period. LPR channel dredging occurred downstream of RM 1.7 as late as 1983 (Fig. 2). In Newark Bay, navigation channel dredging is believed to have last occurred above Port Newark (near RM -2.5) in 1989 (TSI 2011) and has been ongoing in lower Newark Bay as recently as the last several years in conjunction with harbor deepening (USACE 2007; Wakeman et al. 2007). These influences are considered qualitatively in the interpretations below.

Insight into the large-scale historical transport of 2,3,7,8TCDD can be gained by considering within the above conceptual framework the estimated mass inventory in three distinct segments: (1) between RM 2 and RM 4, (2) upstream of RM 4, and (3) downstream of RM 2. The segment between RM 2 and RM 4 contains $57 \%(21 \mathrm{~kg})$ of the estimated $37 \mathrm{~kg}$ trapped in the estuary (Fig. 6a), with about $17 \%(6.3 \mathrm{~kg})$ confined to the Phase I removal area (as previously noted, the mass estimates in Fig. 6 do not account for dredging of the Phase I removal area in 2012, given the focus on long-term HOC fate and transport patterns). Because the RM 2-4 segment contains the Lister Avenue site source, the inventory $M_{\text {bed }}$ there reflects mainly (ignoring air exchange) the difference between the cumulative 2,3,7,8-TCDD loading to the system (third rhs term in Eq. 1) and the net advective fluxes across the upstream boundary at $x_{1}=\mathrm{RM} 4$ and the downstream boundary at $x_{2}=\mathrm{RM} 2$ (first rhs term). This implies that $57 \%$ of the total mass discharged to the estuary was trapped within about 1 mile of the source location at RM 3.1, although the actual fraction is likely less given that the total mass estimate in Fig. 6a does not account for dredging removal or losses to regions beyond the lower Newark Bay bin and to the Hackensack River. The historical net flux through the RM 2-4 segment's upstream boundary at RM 4 is approximately the mass that resides above RM 4, estimated at about $16 \%(5.9 \mathrm{~kg})$ of total system mass. Likewise, the net flux through the segment's downstream boundary at RM 2 may be taken as the $27 \%(9.8 \mathrm{~kg})$ of the total system mass estimated to reside downstream of RM 2. Both the upstream and downstream fluxes are likely lower bound estimates given historical navigation channel dredging subsequent to the Lister Avenue discharge. However, this effect is on a mass basis likely much greater in the downstream direction, given the more extensive dredging, the larger dredge volumes (the channel is wider ${ }^{20}$ and the sedimentation rates implied by Fig. 2 are generally much higher), and the exclusion of losses to the Kills and the Hackensack River from the downstream flux estimate. Nevertheless, the 2,3,7,8-TCDD flux estimates implied by Fig. 6a yield two general fate and transport insights. First, HOCs entering the lower portion of the LPR have historically been subject to an efficient settling sink, given that more than

\footnotetext{
${ }^{20}$ The authorized channel width is $150 \mathrm{ft}(45.7 \mathrm{~m})$ upstream of RM 8 , whereas it is $300 \mathrm{ft}(91.4 \mathrm{~m})$ below RM 2 (USACE 2010). The channel widens further in Newark Bay, particularly below Port Newark (see USACE 2007).
} 
half of the 2,3,7,8-TCDD mass is estimated to have been trapped within 1 mile of the discharge and $73 \%(27 \mathrm{~kg})$ within the lower 6 miles, i.e., in the region of high sediment accumulation (Fig. 2). Second, the slightly skewed mass distribution in Fig. 6a suggests that the net upstream HOC transport processes that occur at low flows [based on the aforementioned net solids flux calculations of Chant et al. (2011) near RM 3] have been dominated by net downstream transport over the long-term. The slight downstream skew in estimated mass fluxes was reduced in an alternate interpolation in which areas inside and outside the channel were interpolated separately (not shown), in an attempt to capture the lateral structure suggested by the core data ${ }^{21}$. In this case, about $63 \%$ of the mass resided in the RM 2-4 bin with $15 \%$ upstream of RM 4 and $22 \%$ downstream of RM 2; longitudinal patterns are qualitatively similar but with more mass trapped between RM 0 to RM 6 (80\% of total) and a $15 \%$ increase in the estimated LPR/Newark Bay mass (about $43 \mathrm{~kg}$ ). Nonetheless, if dredging and losses to the Kills and the Hackensack River were accounted for, the downstream flux skew would likely be significantly enhanced. An evaluation of the upstream and downstream 2,3,7,8-TCDD patterns and the associated transport mechanisms is provided in the sections that follow.

\section{Upstream Transport}

The discussion of upstream transport considers the distribution of 2,3,7,8-TCDD peak concentration and mass upstream of RM 4 (Figs. 4 and 6) as well as the associated ratio of 2,3,7,8-TCDD to total TCDD at the 2,3,7,8-TCDD peak depth (Fig. 5a). The mass in this reach corresponds to approximately $16 \%$ of the total estimated 2,3,7,8-TCDD mass in the LPR and Newark Bay, and four features of its distribution are highlighted. First, there is a decline in the estimated mass inventory per 2-mile segment moving upstream of RM 4, which becomes more pronounced upstream of RM 12. Second, the average maximum concentrations in the RM 4-14 interval are variable and, unlike the estimated mass inventory, lack a clear longitudinal trend. Third, compared to downstream areas, there is little mass inventory upstream of approximately RM 14 and peak concentrations are correspondingly low. Fourth, the fingerprint ratio of 2,3,7,8-TCDD to total TCDD also drops dramatically upstream of approximately RM 14 , suggesting that the dioxin inventory in this region is dominated by background sources, not Lister Avenue site discharges.

\footnotetext{
${ }^{21}$ For example, the mass-per-area estimates are typically higher in cores outside the channel between RM 10 and RM 14 (consistent with silt deposits along the shoals) and in the lower Newark Bay bin (consistent with channel maintenance dredging). Relative to the base interpolation (Fig. 6), the alternate interpolation using Thiessen polygons delineated separately inside/outside of the navigation channel restricts lateral interpolation of cores across channel boundaries but extends the longitudinal interpolation distances.
}

For discussion purposes, we invoke the conceptual framework of Eq. 1 moving upstream of RM 4 on a segment-bysegment basis, setting $x_{1}$ and $x_{2}$ to be the downstream and upstream segment boundaries, respectively (e.g., the RM 4-6 segment would have $x_{1}=\mathrm{RM} 4$ and $x_{2}=\mathrm{RM} 6$ ). For simplicity, the air exchange term and the dredging term are ignored, the latter on the basis of the fairly limited extent of upper LPR channel dredging after Lister Avenue site production years (partial channel dredging of approximately 3 miles between RM 7.9 and RM 14.3 in the 1970s, Fig. 2). The mass inventory for each river segment is thus taken as the net advective flux term in Eq. 1, i.e., the difference between the long-term cumulative fluxes at $x_{1}$ and $x_{2}$. Conceptually, the net flux reflects a combination of two characteristic potentials that are specific to each segment:

1. Transport potential: the potential of upstream transport mechanisms to have delivered 2,3,7,8-TCDD to the segment (i.e., across the boundary $x_{1}$ )

2. Trapping potential: the potential of the segment to have trapped the delivered mass over the long term

Thus, the decline in 2,3,7,8-TCDD mass per segment moving upstream $^{22}$ (Fig. 6a) can generally be interpreted as a concurrent decline in one or both of the above characteristic potentials, with a near-complete loss of one or both of them occurring upstream of approximately RM 14. Because the pattern is similar when expressed on a mass-per-area basis (Fig. 6b), it cannot be attributed to the decline in surface area moving upstream. The discussion below considers each of these characteristic potentials in the context of reconciling the estimated mass distribution with other physical data and past investigations.

The upstream transport of 2,3,7,8-TCDD is consistent with the solids flux calculations of Chant et al. (2011), which indicate a net upstream solids transport during low flow conditions, due to a combination of tidal pumping and the estuarine circulation. At RM 3 (i.e., near the Lister Avenue site), this upstream net solids flux was found to occur under present day conditions for freshwater flow rates lower than about $30-40 \mathrm{~m}^{3} / \mathrm{s}$ (approximately the mean flow), increasing with decreasing flow and increasing tidal range. Chant et al. (2011) also concluded that the upstream solids flux associated with tidal pumping dominated that of the estuarine circulation at RM 3, reflecting a flood-dominant asymmetry of tidal currents (near-bottom and depth-averaged). The strength of each transport mode can be expected to vary moving upstream

\footnotetext{
$\overline{22}$ Although our focus is here on large scale trends, we note that the segment-by-segment decline upstream of RM 4 is not quite monotonic given the higher mass estimate for RM 8-10 bin relative to its downstream neighbor. Local differences in the long-term trapping potential could give rise to a nonmonotonic pattern, but it is more likely a consequence of the lower core density in this reach (as reported in Fig. 6a) and the interpolation.
} 
and eventually decay near the salt front, which marks both the limit of the net landward bottom flow associated with the gravitational circulation and the density gradients that can induce flood-dominant "internal" tidal asymmetry ${ }^{23}$ (e.g., Jay and Musiak 1996; Burchard and Baumert 1998). A flow-dependency of the direction of the net solids flux was also reported at various LPR locations by SEI and HQI (2011) as well as Mathew et al. (2011, unpublished), who further noted that the decline in the transition flow with distance upstream was consistent with model predictions of salt front intrusion. Moreover, the observations presented in Chant et al. (2011) clearly indicate the formation of an estuarine turbidity maximum (ETM) near the salt front, suggesting enhanced solids deposition/trapping and the likely formation of a "mobile pool" (Geyer 1993). Both upstream solids transport modes as well as the conditions associated with the ETM (e.g., vertical mixing, high solids concentrations, flocculation, settling; see Dyer 1995) imply an upstream delivery of HOCs originating from downstream during low flow conditions. However, as previously noted, net HOC transport is subject to additional considerations beyond the net solids flux. The demonstrated influence of partitioning behavior on predicted contaminant transport near an ETM (Uncles et al. 1988) suggests that net HOC transport will be generally sensitive to factors influencing the exchange between the dissolved and particulate phases (e.g., sorption kinetics as well as the concentration, composition, and setting rates of suspended particles). Bed processes influencing the vertical exchange of HOCs in near-surface sediments (including the communication between unconsolidated sediments at the sediment-water interface and the underlying parent bed) are presumably also

\footnotetext{
${ }^{23}$ Tidal asymmetry in the flow field may be decomposed into "barotropic" and "internal" constituents, where the latter arises due to the interaction of tidal currents with a longitudinal density gradient; nearbottom currents may be enhanced on flood relative to ebb by the combined influence of barotropic and baroclinic pressure gradients as well as tidal variations in stratification and vertical mixing (Jay and Musiak 1996). A flood-dominant asymmetry in tidal currents implies a potential for upstream tidal pumping of solids due to two main effects (e.g., Dronkers 1986): (1) peak bottom shear stresses are greater on flood than on ebb, implying greater potential for resuspension; and (2) the period near slack water is longer on flood than on ebb, implying greater settling/ consolidation on flood. In addition, tidal asymmetry in stratification induces greater vertical mixing of solids on flood relative to ebb, which strongly promotes net upstream solids transport and trapping (e.g., Geyer 1993; Jay and Musiak 1996; Burchard and Baumert 1998, Chant and Stoner 2001, Scully and Friedrichs 2003, Winterwerp 2011). The balance of mechanisms influencing net sediment transport by tidal pumping is complex and additional considerations apply, such as lag effects, flocculation dynamics, availability of resuspendable sediment, topographical effects, and lateral asymmetries (see Dyer 1995; Chant and Stoner 2001; Scully and Friedrichs 2007; Winterwerp 2011). Net upstream tidal pumping of solids above the salt front (e.g., by barotropic tidal asymmetry - see Allen et al. 1980; Uncles et al. 1985; Uncles and Stephens 1989) is here presumed minor, given observations of the turbidity maximum near the salt front, low flow bottom current patterns, and solids flux calculations by other LPR investigators (all discussed below).
}

important, to the extent that they dictate the concentration on resuspended particles as well as the relative importance of dissolved and particulate phase HOC flux from the bed. Likewise, horizontal gradients in bed concentrations can influence net HOC transport, e.g., tidal dispersion can yield a net HOC flux in the absence of a net solids flux if bed concentrations vary over the scale of a tidal excursion, even upstream of the salt front since tidal asymmetry is not required. ${ }^{24}$ Nonetheless, because the upstream 2,3,7,8-TCDD mass distribution appears qualitatively consistent with solids flux considerations, the discussion below mostly ignores the distinction in transport mechanisms between HOCs and solids.

Both the decline in upstream 2,3,7,8-TCDD mass inventory and the apparent upstream transport limit of approximately RM 14 are consistent with salt front intrusion. The nearbottom high tide salt front position as a function of flow was characterized in Chant et al. (2011) using the 2 psu isohaline (based on shipboard surveys in 2004 and 2005) and in SEI and HQI (2011) using the 0.5 psu isohaline (based on hydrodynamic model predictions of the period 1994-2004). Using these relationships, we estimated ${ }^{25}$ the approximate flows at which the 2 and 0.5 psu isohalines would reach the segment boundaries considered in Fig. 6, and converted flows to cumulative frequencies of salinity intrusion using the historical flow record (post-1948) at Little Falls (Fig. 7). For reference, Chant et al. (2011) observed the 2 psu isohaline at approximately RM 11 during a $1.2 \mathrm{~m}^{3} / \mathrm{s}$ flow $(\mathrm{P} \approx 1.8 \%)$ with an ETM somewhat further upstream near RM 12. Also shown in Fig. 7 is the observed frequency of these salinity thresholds in the maximum daily salinity record at five ADCP/CTD moorings that were deployed along the LPR for two surveys spanning October 2009 to July 2010 (the mean and median flows at Little Falls for sampling days were approximately 40 and $20 \mathrm{~m}^{3} / \mathrm{s}$, fairly similar to the long-term flow record values of 33 and $18 \mathrm{~m}^{3} / \mathrm{s}$ ). Although the estimated salt front intrusion frequencies in Fig. 7 are approximate in nature, they are qualitatively consistent with the 2,3,7,8-TCDD concentration and mass distributions (Figs. 4, 5a, and 6) in that the intrusion frequency is here estimated to be about $5 \%$ or less for RM 12 and about $1 \%$ or less for RM 14 . Relative to present day conditions, the probabilities of salt front intrusion were likely somewhat higher during the time of peak $2,3,7,8$-TCDD loading when less infilling had occurred in the lower river (see Chant et al. (2011) for the supporting scaling arguments for this bathymetry effect, which has also been confirmed via

\footnotetext{
${ }^{24}$ A sediment transport analogue of this effect is longitudinal gradients in bed properties or the presence of a "mobile pool" upstream of the salt front, which could contribute to ETM formation somewhat upstream of the salt front while the bed properties adjust (see discussion in Uncles and Stephens 1989; Geyer 1993; Le Hir et al. 2001).

${ }^{25}$ A mid-range critical flow was estimated for each segment boundary by visual inspection of Fig. 9 in SEI and HQI (2011); therefore, the numbers are approximate only.
} 
Fig. 7 Estimates of salinity intrusion frequency in the LPR, using the flow relationship from Chant et al. (2011) and modeling results from SEI and HQI (2011; visually estimated from figure therein) together with the historical hydrograph, and maximum daily bottom salinity from mooring deployments in 2009 and 2010

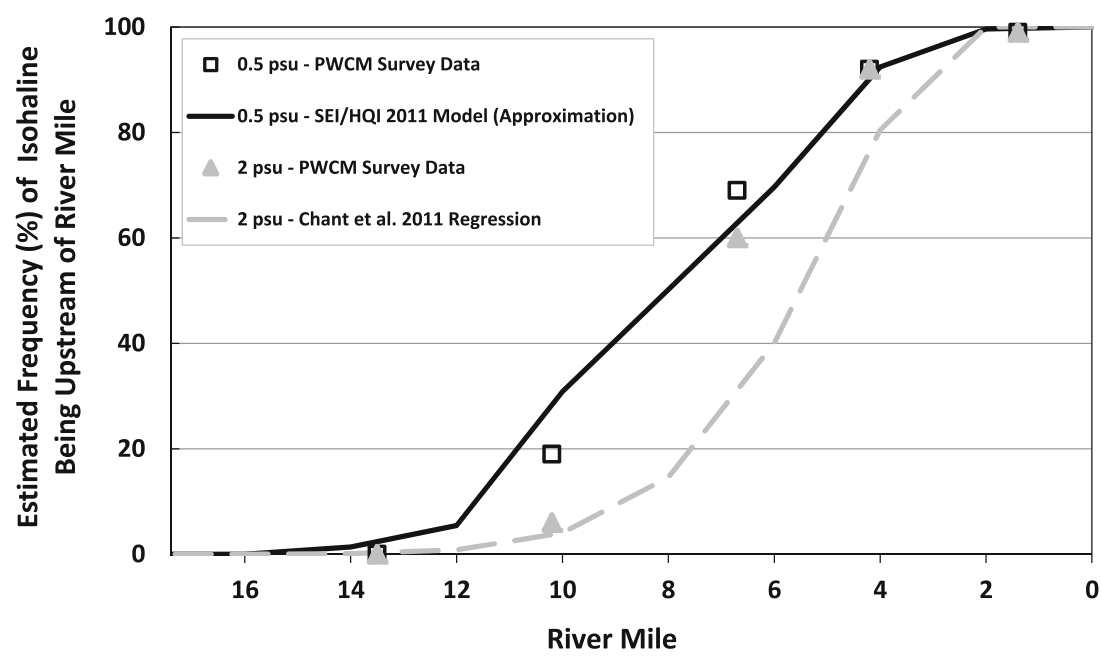

hydrodynamic simulation (unpublished results from Canizares et al. 2009)). Moreover, enhanced salinity intrusion would be expected during the drought conditions that prevailed in the early-to-mid 1960s (Chant et al. 2011).

Current velocity measurements from a low flow period in July 2010 suggest that the upstream decline in 2,3,7,8-TCDD mass inventory is also consistent with the decreasing strength of the upstream transport modes moving along the LPR. The velocity records at the five $\mathrm{ADCP}$ moorings noted above were analyzed over the low flow period spanning July 3-12, 2010 (mean flow of approximately $3.6 \mathrm{~m}^{3} / \mathrm{s}, P \approx 12 \%$ ), during which the salt front was visible at the RM 10.2 station on each high tide [maximum bottom salinity in the $1-4$ psu range (not shown)] but never reached the RM 13.5 station (using a $0.5 \mathrm{psu}$ threshold). The net upstream bottom flow of the estuarine circulation, as inferred from the time-averaged longitudinal velocity in the bottom ADCP bin (Fig. 8a), was nominal by the RM 10.2 station and vanished by the RM 13.5 station, following a decline from its peak strength at the RM 4.2 station (note that the bottom bin for these upwardfacing ADCPs was approximately $1 \mathrm{~m}$ off the bed and no extrapolation has been performed in Fig. 8). Likewise, the data suggest a drop off in the tidal pumping of solids moving upstream, as inferred from the trend in tidal asymmetry of the average peak flood and peak ebb longitudinal velocities (Fig. 8b). The flood tide peak velocity decreases moving above RM 6.7, both in absolute terms and relative to the ebb tide peak velocity, declining from its maximum asymmetry at the RM 4.2 station. By the RM 13.5 station, the peak bottom velocity is nearly symmetrical. The mean tidal excursion also declines moving upstream [e.g., going from a neap-spring range of approximately 2-4 miles at RM 10.2 to a range of approximately 1-2.5 miles at RM 13.5 (based on time integration of the depth-averaged velocities during this period; not shown)]; as such, longitudinal tidal mixing also decreases upstream. It is again noted that the upstream transport modes were likely stronger in the past before channel infilling in the lower LPR, as suggested by the historical salt front intrusion arguments of Chant et al. (2011).

Lastly, the estimated 2,3,7,8-TCDD mass accumulation pattern upstream of RM 4 also appears consistent with sediment grain size trends, which we take as an indicator of the long-term HOC trapping potential on the expectation that bed composition will reflect the long-term shear stress environment. A 2004 side scan sonar survey qualitatively suggests a decreasing trapping potential moving upstream of RM 8 , as

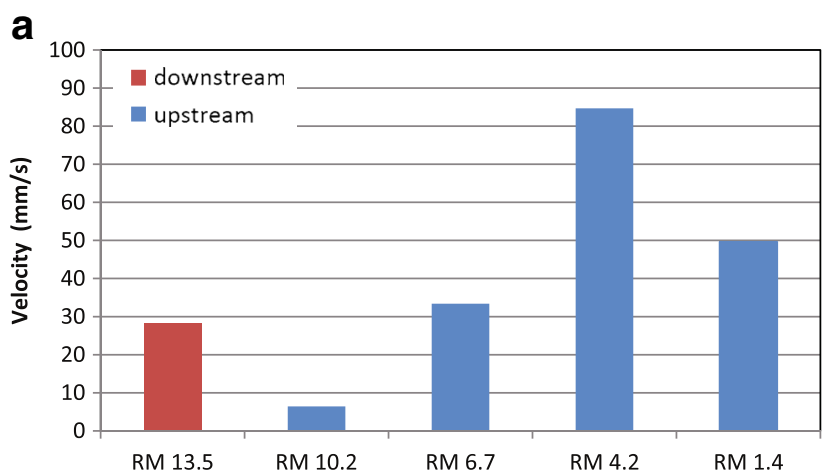

a

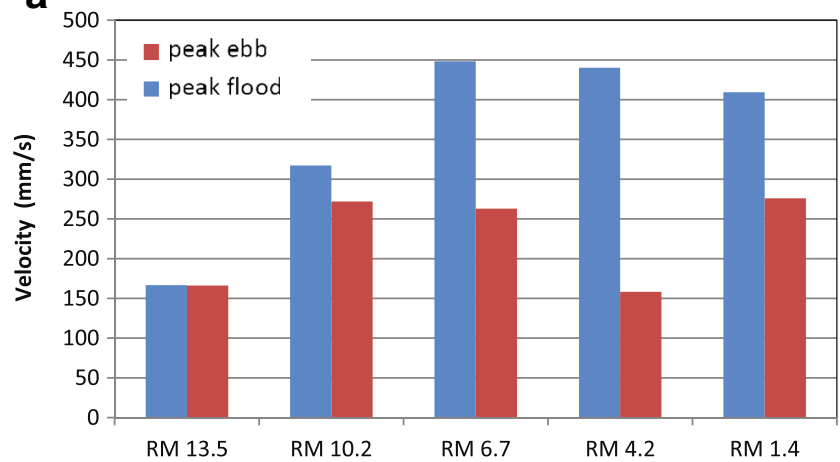

Fig. 8 Time-averaged current velocity in the bottom bin of five ADCP moorings spaced along the LPR, for the low-flow period from July 3 to 12, 2010: a Overall mean velocity and $\mathbf{b}$ Mean peak flood and peak ebb tide velocity 
inferred by the generally decreasing prevalence of finegrained deposits, especially above RM 14 (not shown; see MPI 2007). Likewise, there is a decrease of average surficial fine sediment fraction with distance upstream, most notably within the navigation channel (Fig. 9a). The trend suggests that fine material deposited during low flows is more likely to be scoured during high flows from the navigation channel than from outside of it, and more so in the upper LPR than in the lower reaches, consistent with expected lateral and longitudinal high flow shear stress trends moving downstream [the depth and cross-sectional area increase downstream (see Fig. 1, Chant et al. 2011) and as previously noted the lower 8 miles have on average been highly depositional (subject to local variability; Figs. 2 and 9b)]. Thus, the declining longitudinal trend in 2,3,7,8-TCDD mass accumulation moving upstream from the source is consistent with a reduced trapping potential of fine solids. Moreover, it is noted that the trends in inferred trapping potential are consistent with the observation that 2,3,7,8-TCDD mass-per-area estimates and maximum concentrations in the interval RM 10-14 are typically higher outside of the navigation channel.

To summarize, the distribution of 2,3,7,8-TCDD mass inventory upstream of RM 4, including the absence of significant accumulation upstream of approximately RM 14, appears consistent with both the expected salt front intrusion and associated upstream transport modes (acknowledging that they were likely more efficient in the past) as well as the inferred trapping potential of upstream areas. The analysis does not distinguish which effect is dominant, though they are unlikely to be independent of each other. The upstream processes that delivered 2,3,7,8-TCDD to the upper reaches are presumably also critical in the upstream delivery of fine solids and the regulation of a "mobile pool" [including contributions from Newark Bay and from the UPR, transported upstream after settling in the lower LPR (see Dyer 1995 or Schubel and Carter 1984 for general reference)].

\section{Downstream Transport}

The longitudinal 2,3,7,8-TCDD mass distribution (Fig. 6a) indicates that approximately $27 \%$ of the total estimated mass in the LPR and Newark Bay resides below RM 2, and three additional features of its distribution are highlighted. First, there is a monotonic decline in the average maximum concentration downstream of RM 2 as well as the estimated mass per area (Figs. 4 and 6b). Second, the ratio of 2,3,7,8-TCDD to total
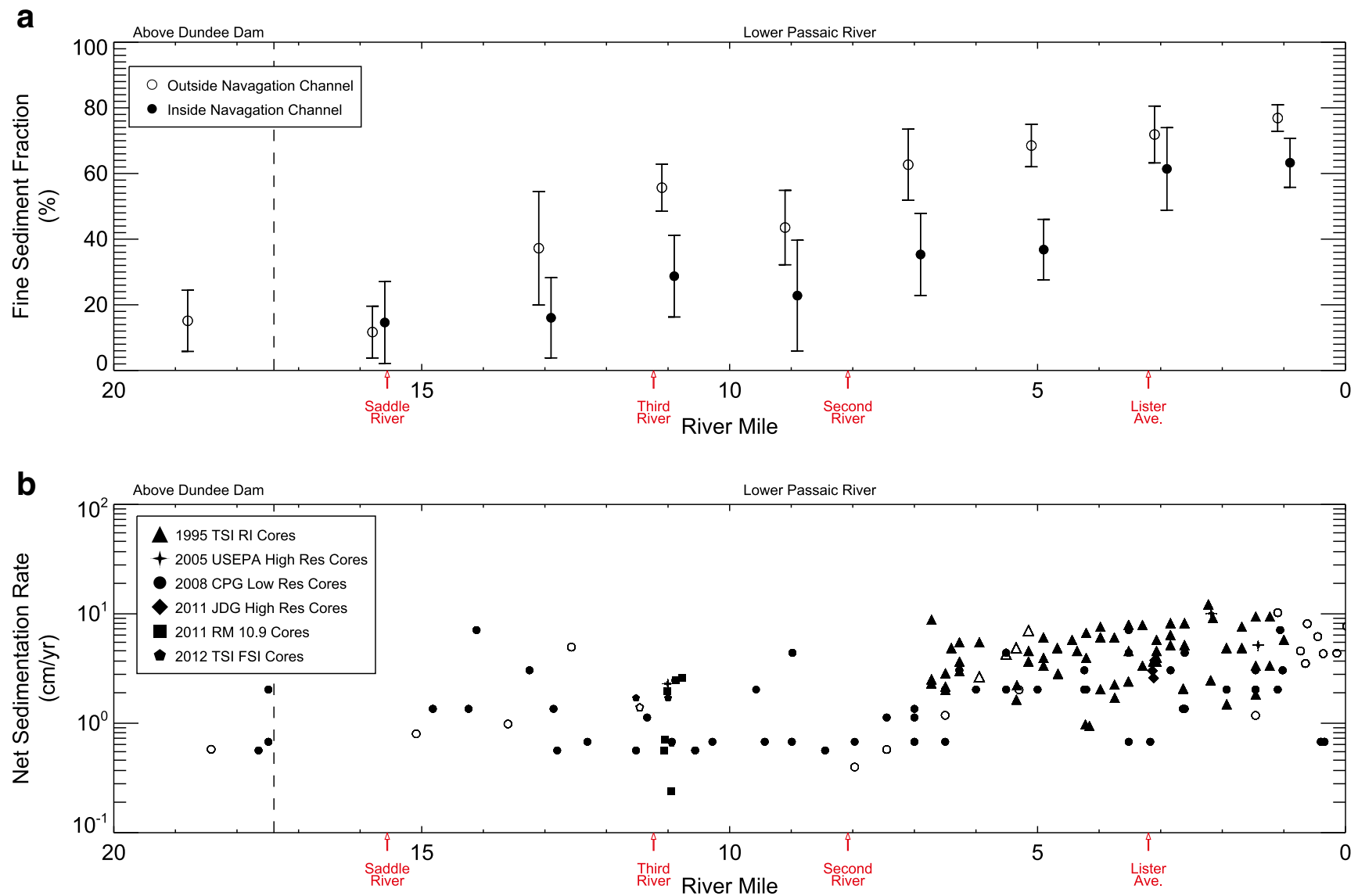

Fig. 9 a Fine solids fraction in surface sediments (mean \pm 2 SE, using post-2000 datasets). b Net sedimentation rates from geochronology; for the 1995 and 2008 datasets, open symbols indicate estimates with greater uncertainty 
TCDD at the 2,3,7,8-TCDD peak also declines downstream, most notably within the navigation channel (open symbols in Fig. 5a). Third, despite the weakening of the LPR signal, the ratio in lower Newark Bay remains above the range associated with background dioxin sources ( 0.06 or less based on Chaky 2003).

Conceptually, the framework of Eq. 1 may again be applied, but here the mass inventory has been more strongly influenced by dredging (fourth rhs term) in addition to the net advective flux (first rhs term). Building on the upstream transport discussion, the mass in each segment below RM 2 reflects mainly the potential of downstream transport mechanisms to have delivered 2,3,7,8-TCDD across the upstream boundary of the segment (transport potential), the potential of that segment to have trapped the delivered mass over the long-term (trapping potential), and the extent of dredging within the segment. Given that the deep navigation channels downstream of RM 2 were highly depositional during peak 2,3,7,8-TCDD loading and were subsequently dredged, coupled with the previously noted exclusion of losses to the Hackensack River from the present analysis, the comments below are restricted to general observations pending more detailed analysis of Newark Bay physical and chemical datasets.

The larger estimated mass fraction trapped downstream of RM 2 (about $27 \%$ after significant dredging, plus losses to the Hackensack River and the Kills) relative to upstream of RM 4 (16\% after comparatively nominal dredging) is qualitatively consistent with expectations from sediment transport considerations. The analysis by Chant et al. (2011) indicates a net downstream solids flux at RM 3 during moderate to high freshwater flow conditions (above approximately $40 \mathrm{~m}^{3} / \mathrm{s}$ under present day conditions), which dominates the more persistent low flow upstream flux over the long term. Although the net solids flux reflects a combination of boundary loading and inriver resuspension, the balance between upstream and downstream transport is likely important to HOCs as well, causing some contaminant moved upstream during low flows to be remobilized during high flow from areas with insufficient long-term trapping efficiency. Contaminant mass accumulation would be expected in the generally more favorable trapping conditions in the expanded cross-sections of the lower LPR and upper Newark Bay [i.e., as indicated by the increasing net sedimentation rates and fine sediment fractions moving downstream (Fig. 9) and the pronounced infilling that has occurred in the navigation channels, particularly downstream of RM 2 and in northwestern Newark Bay where the channel was maintained into the 1980s; see bathymetric comparisons in Fig. 2, USACE (2007), and Sommerfield and Chant (2010)]. The sediment trapping efficiency above RM 2 was significantly higher during the time of the Lister Avenue site discharges but decreased over time as the LPR channel filled in (see Chant et al. 2011), and the mass distribution in Fig. 6 combined with the dredging history suggests that the integrated fluxes over time favored more 2,3,7,8-TCDD accumulation below RM 2 than above RM 4.

Setting aside the confounding factors of dredging and HOC-specific transport considerations (discussed below), the declining influence of 2,3,7,8-TCDD from the LPR with distance downstream is consistent with a settling and solids mixing signature, and more specifically with the following two solids transport considerations. First, while episodic high flow events contribute to more widespread transport of LPR sediments in Newark Bay, the probability of a hydrologic event capable of delivering significant amounts of LPR solids to a given location should generally decrease moving across the Bay, notwithstanding the complexities of circulation and sediment transport responses to the freshwater flow, wind, and tidal forcings (see Chant 2006; Pecchioli et al. 2006; Pence et al. 2005; Wakeman et al. 2007; Sommerfield and Chant 2010). Second, there is under most conditions a net northward (landward) solids transport along the navigation channel in Newark Bay toward the LPR and the Hackensack River due to a combination of tidal pumping and gravitational circulation, and even during high flow events settling LPR solids may be transported by the intensified net northward near-bottom flow (Chant 2006; Pecchioli et al. 2006; Sommerfield and Chant 2010). The above processes imply that, moving across Newark Bay, the sediment bed reflects a declining fraction of solids originating from the LPR, which is consistent with the noted concentration and mass trends. Likewise, the greater dilution of the LPR signal within the navigation channel than outside of it [as characterized by the ratio of 2,3,7,8-TCDD to total TCDD at the 2,3,7,8-TCDD peak (Fig. 5a)] is consistent with the strong solids import from Kill van Kull along the navigation channel, and the generally low sedimentation on the subtidal flats that comprise $70 \%$ of the Newark Bay area (where tidal and wind-driven resuspension is thought to limit accretion; see Wakeman et al. 2007 and Sommerfield and Chant 2010). The trends are also consistent with the observation that maximum 2,3,7,8-TCDD concentrations are on average higher outside than inside the navigation channel in the lower Newark Bay bin (not shown) despite the likely channel trapping of sediments resuspended from the sub-tidal flats (Wakeman et al. 2007 and references therein); however, the noted differences between the channel and flats may also simply reflect the removal of sediments from the peak Lister Avenue site discharge era during subsequent navigation channel dredging.

Beyond solids transport considerations, the dynamics of HOC trapping under all flow conditions may be influenced by the following additional effects as Newark Bay is approached: (1) volumetric dilution of HOC concentration; (2) the interaction of LPR solids with other suspended solids (e.g., from Newark Bay, Kill van Kull, Arthur Kill, and the Hackensack River); and (3) enhanced partitioning of HOCs to solids due to higher salinity (e.g., Uncles et al. 1988). Although subject to 


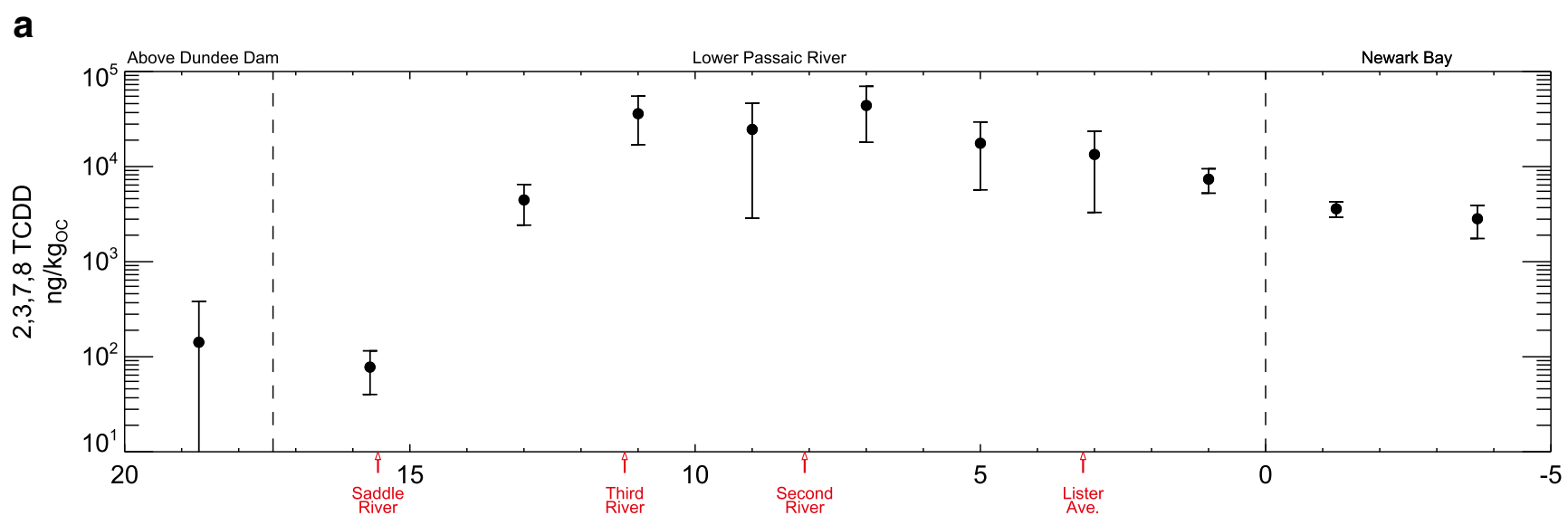

b

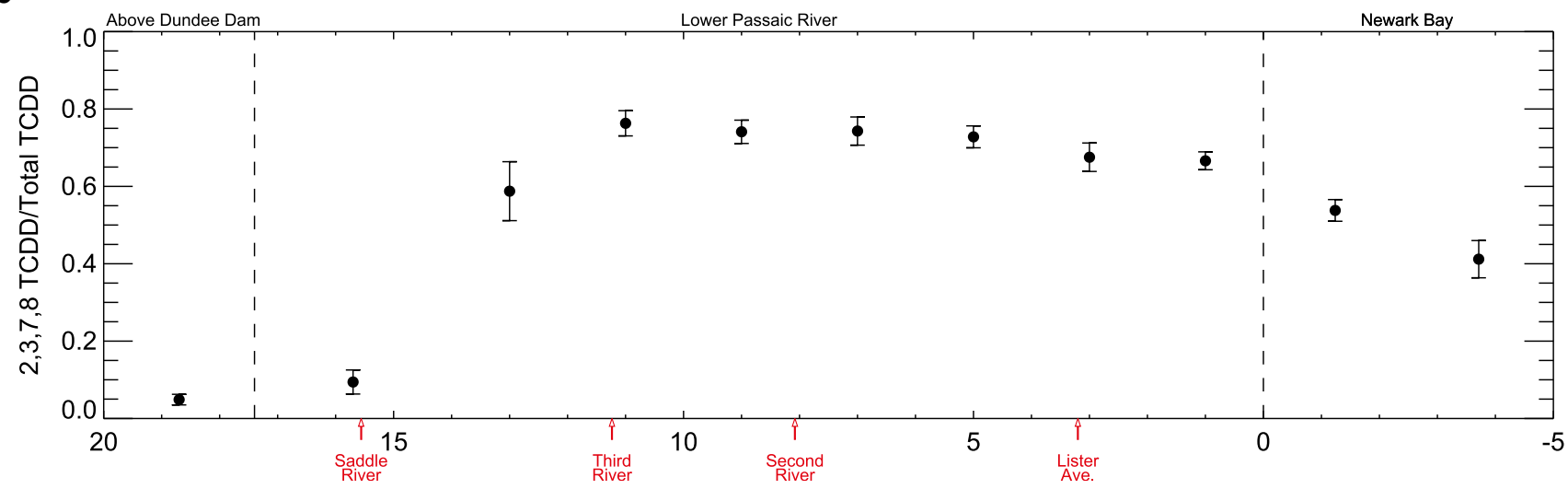

Fig. 10 Longitudinal surface sediment distribution of (mean $\pm 2 \mathrm{SE}$, using post-2000 datasets): a OC-normalized 2,3,7,8-TCDD concentration; $\mathbf{b}$ ratio of 2,3,7,8-TCDD to total TCDD. Surface sediment is defined

lag effects associated with desorption kinetics ${ }^{26}$ and particle settling, these processes could influence the sorbed concentration on suspended particles with distance downstream (presumably volumetric dilution would favor greater flowthrough of the dissolved phase, whereas the other two effects would enhance settling). In addition, the net HOC transport associated with tidal pumping of solids in the lower miles of the LPR and upper Newark Bay may be modified by longitudinal concentration gradients on the scale of a tidal excursion. ${ }^{27}$ The relative influence of each process, along with the other factors that impact trapping, cannot be inferred from the bed contaminant patterns relied upon by our "indirect method" of inferring transport dynamics. Ongoing investigations

\footnotetext{
${ }^{26}$ In the case of 2,3,7,8-TCDD, partitioning effects in the water column may be limited given the desorption timescales of days to months reported by Sormunen et al. (2009), which are long relative to expected settling times of suspended particles.

${ }^{27}$ At the RM 1.4 ADCP station, a neap-spring range in mean tidal excursion of about 2.5-5 miles was estimated via time integration of the depth-averaged velocities for a low flow period in July 2010 (not shown); the actual tidal excursion is likely influenced by the longitudinal geometry changes in this region.
}

as $0-6$ in. $(15.24 \mathrm{~cm})$; most datasets used a surface slice of this thickness but the figure includes shallower samples where available

of solids and contaminant fluxes in the water column and contaminant fate and transport modeling should in the future reveal additional insights.

\section{Recovery of Surface Sediments Following Source Control}

The preceding sections have focused on maximum concentration and mass inventory patterns that reflect mainly the historical transport and trapping of 2,3,7,8-TCDD following peak discharges from the Lister Avenue site. Present-day surface sediment concentrations $(0-15 \mathrm{~cm}$; Fig. 10a) indicate that a large-scale recovery of mean concentrations has occurred since the time of the Lister Avenue site discharge; below RM 12, surface concentration averages are about 320 times lower than the mean peak concentrations (Fig. 4a). However, the data also indicate that the rate of recovery has not been spatially uniform. In particular, the longitudinal distribution of mean surface 2,3,7,8-TCDD concentration in Fig. 10a differs markedly from the mean peak distribution (Fig. 4a), cresting in the RM 6-12 reach rather than near the Lister Avenue site at RM 3; a similar trend is visible though less pronounced in the ratio of $2,3,7,8-\mathrm{TCDD}$ to total TCDD 
Cores immediately adjacent to Lister Avenue site

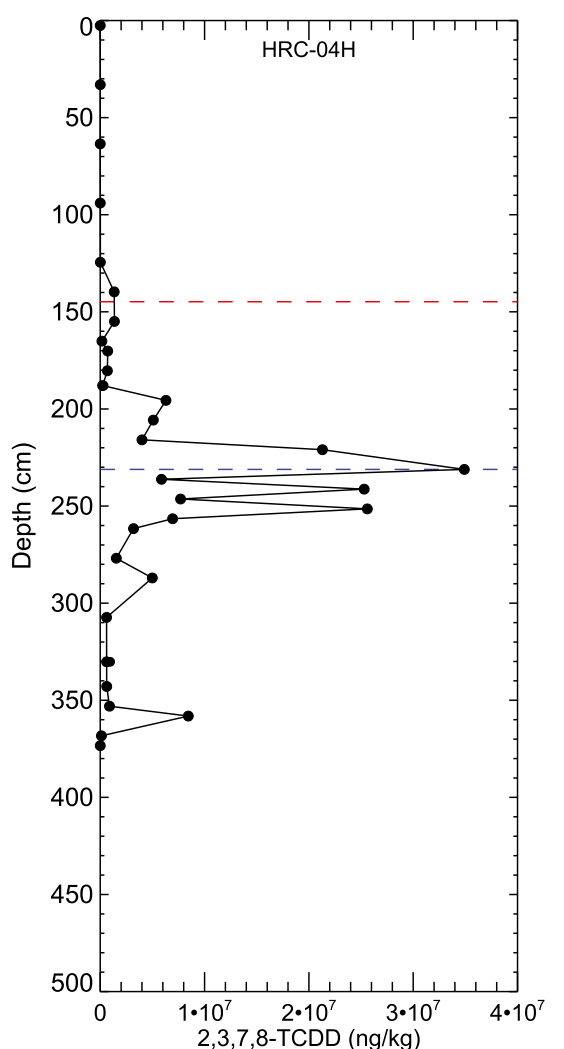

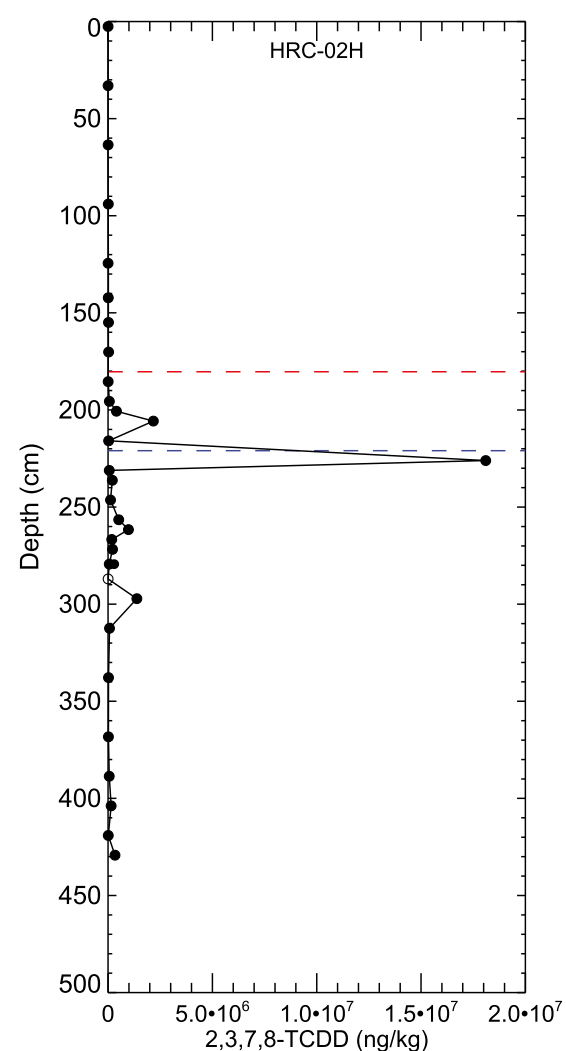

Core further from shore

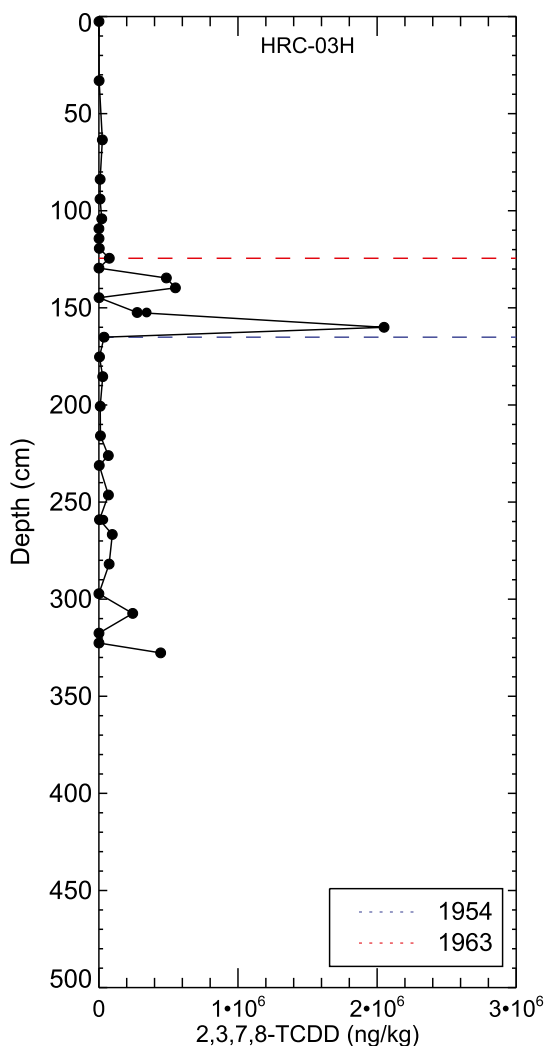

Fig. 11 Concentration profile of 2,3,7,8-TCDD in the three 2011 JDG high resolution cores collected near the Lister Avenue site (estimated Cs-137 horizons are also shown)

(Fig. 10b). Although the inferred mean recovery likely occurs due to a combination of factors and may be influenced by the higher data density of the surface sediment dataset, to first order, both the large-scale concentration decline and the longitudinal gradient in recovery are consistent with net sedimentation patterns (i.e., burial), as described below.

The role of sedimentation in past surface sediment recovery is clearly illustrated by three 2011 high resolution cores collected near the Lister Avenue site in strongly depositional environments (Fig. 11). These cores experienced between 2.6 and $3.8 \mathrm{~cm} /$ year of net sedimentation over the past half century (based on Cs-137 dating), which is not unusual in the predominantly fine sediments (Fig. 9a) of the lower 7 miles of the LPR based on sedimentation rates inferred from other geochronological cores (Fig. 9b; also Huntley et al. 1997) and from the difference between recent bathymetry and the navigation channel depth that was historically maintained (Fig. 2). In each of these three cores, the timing of the concentration peak coincides with the Lister Ave discharge, ${ }^{28}$ and surface concentrations are several orders of magnitude lower

\footnotetext{
${ }^{28}$ The Lister Ave site production of 2,4,5-trichlorophenol and 2,4,5trichlorophenoxyacetic acid (2,4,5-T) spanned the period 1948-1969, as previously noted. The core profiles suggest that discharge levels were lower in the 1960s, which would be consistent with the plant upgrade that occurred after an explosion in 1960 (Chaky 2003).
}

than the peaks. The core profiles indicate that the continual deposition of solids that effectively trapped 2,3,7,8-TCDD in the past has subsequently buried peak concentrations and had a diluting effect on surface sediments. The time evolution of this "natural recovery" of surface sediments is evident when 2,3,7,8-TCDD levels are normalized to the concentration corresponding to 1970 (i.e., immediately after 2,4,5trichlorophenol production at the Lister Avenue site ceased; Fig. 12a); in all three cores, surface concentrations in 2011 are about 10-50 times lower than those estimated for 1970. A similar though somewhat less pronounced concentration decline is observed in three high resolution cores collected by USEPA in 2005 at RM 1.4, RM 2.2, and RM 11.0 (where 2005 concentrations are about 5-10 times lower than in 1970; Fig. 12b). The steady decline observed in all six cores is consistent with surface sediment recovery by burial (i.e., deposition of less contaminated solids), with differences in the rate of decline being attributable to factors such as variations in net sedimentation rates and perhaps proximity to areas with elevated surface concentrations.

Moving beyond strongly depositional cores, the data suggest a broad-scale link between 2,3,7,8-TCDD surface sediment concentrations and net sedimentation patterns. In particular, the difference between the mean surface 2,3,7,8-TCDD trend (Fig. 10a: mild gradient between the RM 6-12 interval 

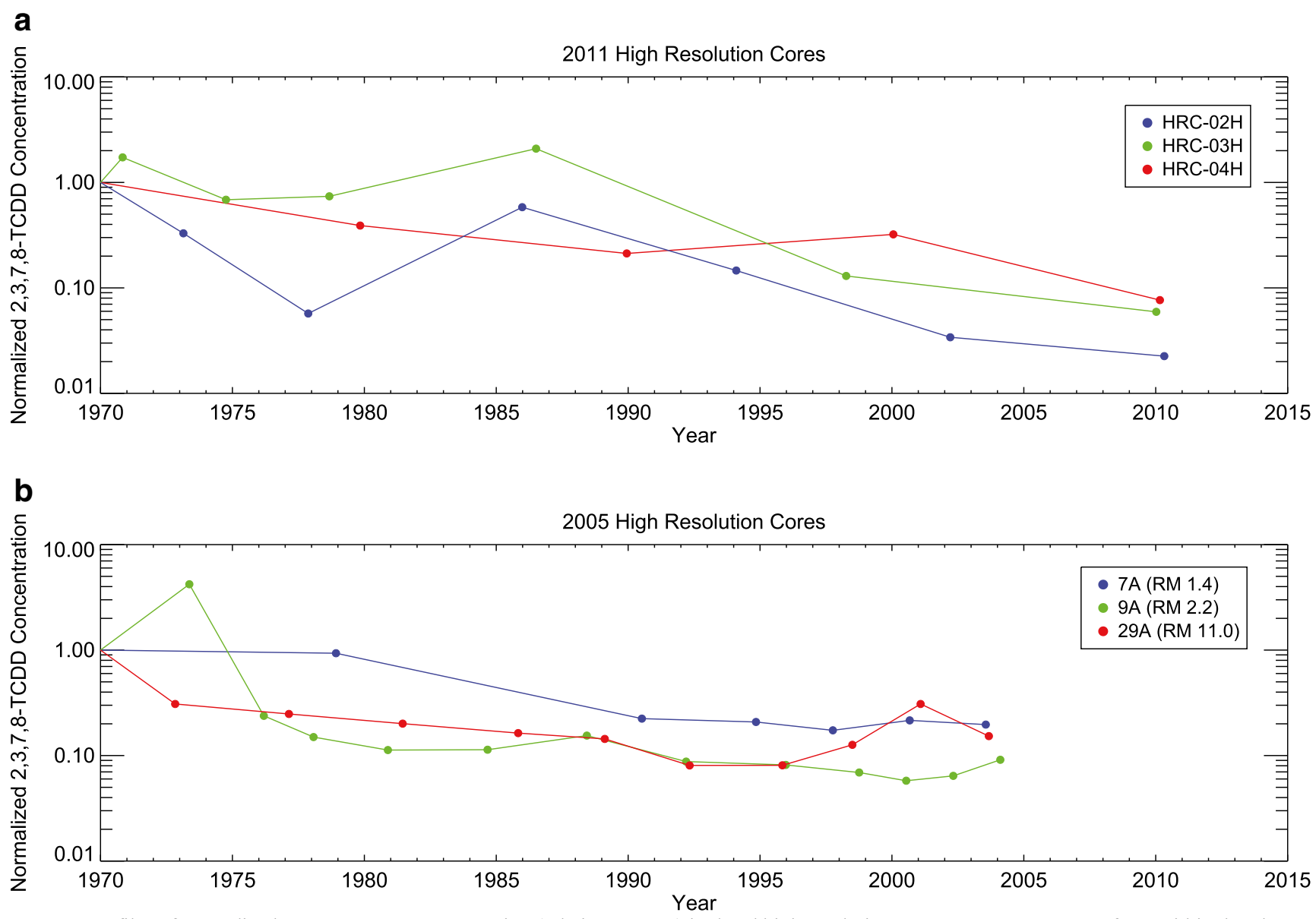

Fig. 12 Profiles of normalized 2,3,7,8-TCDD concentration (relative to 1970) in dated high resolution cores: a 2011 JDG cores from within the Phase I removal area and b 2005 USEPA resolution cores from various locations along the LPR (see legend)

and the mouth of the LPR) and the peak 2,3,7,8-TCDD concentration trend (Fig. 4a: maximum near the Lister Avenue site source at RM 3 and fairly uniform across the lower 14 miles) is qualitatively consistent with the spatial distribution of net sedimentation rates (Fig. 9b: rates are highest near the LPR mouth, remain elevated across the lower 7 miles, and are variable but generally lower from RM 7 to RM 14; see also Fig. 2 for navigation channel infilling below RM 8). The hypothesis that differential burial is a key factor in the present-day surface concentration distribution is supported by the following observations summarized in Fig. 13a-d ${ }^{29}:$ (1) There is a clear relationship between net sedimentation rate and the depth of maximum 2,3,7,8-TCDD contamination in the LPR below RM 14 (Fig. 13c); and (2) cores with high sedimentation rates tend to have lower and less variable

\footnotetext{
${ }^{29}$ Figure 13 shows post-2000 core datasets only. The upper and bottomleft panels consider only cores for which a net sedimentation rate was available via geochronology, whereas the bottom right panel considers all cores in these datasets. The 1995 TSI RI cores also have available geochronology and exhibit similar relationships, but are not included because their typically higher surface concentrations tend to mask overall trends when lumped with later datasets.
}

surface concentrations than low sedimentation rate cores (Fig. 13b) but not lower peak concentrations (Fig. 13a), i.e., they exhibit more consistent recovery. Put another way, the highest surface concentrations tend to be associated with cores with low net sedimentation rates. ${ }^{30}$ Furthermore, core data indicate that widespread recovery of the 2,3,7,8-TCDD peaks has occurred with surface concentrations that are often an order of magnitude or more lower than the peak (Fig. 13d). Thus, the stronger decline in average surface 2,3,7,8-TCDD concentration in the lower 6 miles relative to upstream areas is consistent with enhanced burial in the lower LPR. Between RM 6 and RM 12, the highest surface concentrations tend to be associated with fine sediment deposits along the shoals, suggesting that the inferred slower mean recovery is controlled by these areas; one example of such a deposit is located near RM $10.9^{31}$ where high peak 2,3,7,8-TCDD

\footnotetext{
${ }^{30}$ We note that the converse is not true: Low sedimentation rate does not necessarily imply high surface concentration. As discussed below, burial is not the only recovery process active in the LPR, and low sedimentation rate cores may have accumulated lower concentrations to begin with.

${ }^{31}$ The RM 10.9 mudflat has been extensively sampled as part of a preremedial design program; remediation occurred in fall 2013.
} 
Fig. 13 Evaluation of 2,3,7,8TCDD profiles in cores collected between RM 0 and RM 14: a maximum 2,3,7,8-TCDD concentration versus net sedimentation rate; $\mathbf{b}$ surface 2,3,7,8-TCDD concentration versus net sedimentation rate; $\mathbf{c}$ depth of maximum $2,3,7,8-$ TCDD concentration versus net sedimentation rate; $\mathbf{d}$ maximum versus surface $2,3,7,8$-TCDD concentration (includes cores without an available sedimentation rate estimate). The coring datasets used are provided in the legend of $\mathbf{d}$
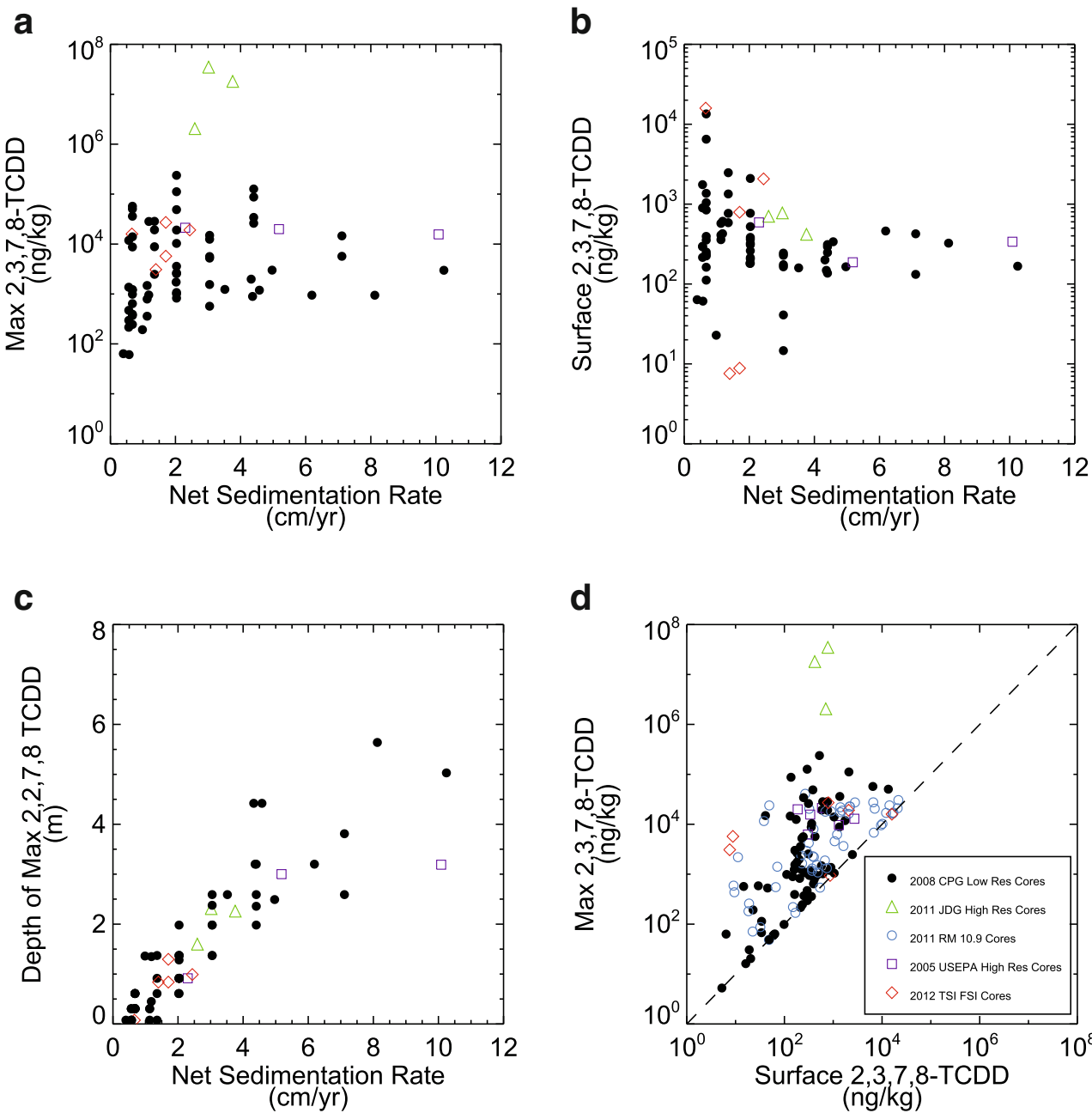

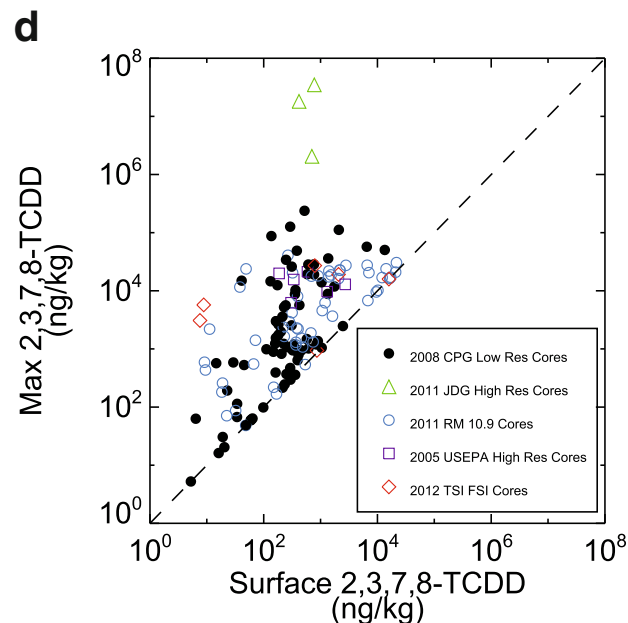

concentrations have occurred in the $0-15 \mathrm{~cm}$ surface samples (see Fig. 13d, blue symbols along the 1:1 line). More generally, the core dataset in Fig. 13d indicates numerous locations throughout RM 0-14 for which the peak resides in the top $15 \mathrm{~cm}$, indicating little net sedimentation and possibly net erosion into previously buried deposits; the higher concentration subset of these cores tend to occur outside the navigation channel (not shown). We note that the same general considerations can be applied to the spatial distribution of the ratio of 2,3,7,8-TCDD to total TCDD (Fig. 10b); here, the longitudinal gradient in the mean presumably reflects differential dilution of the Lister Avenue site fingerprint by cleaner solids that are more influenced by dioxins of a different origin (i.e., with a lower fraction of 2,3,7,8-TCDD).

The preceding observations are not meant to imply that net sedimentation is the only recovery process active within the LPR; recovery in the absence of net sedimentation is expected in areas that experience periodic erosion and deposition, given surface sediment mixing processes (e.g., bioturbation) and the diluting influence of solids originating from the UPR, tributaries, and Newark Bay (Figs. 4 and 10a). Chant et al.
(2011) demonstrate at RM 3 a transition from net upstream to net downstream solids flux at approximately the mean flow, suggesting upstream solids accumulation during low flows and remobilization during high flows. Other LPR investigators have also demonstrated the flow dependence of the net solids flux direction at several additional lower LPR locations (Mathew et al. 2011), and have further identified, on the basis of sequential multibeam bathymetric surveys, areas within the LPR experiencing varying degrees of periodic erosion/deposition in response to the hydrograph (Winterwerp et al., unpublished results). Likewise, Sommerfield and Chant (2010) conclude sediment reworking by tidal resuspension/deposition and perhaps ship scour in northwestern Newark Bay on the basis of Beryllium-7 measurements. The associated surface sediment dilution is likely contributing to the apparent spatial recovery gradient, perhaps contributing to the observation that low net sedimentation rates are not exclusively associated with elevated surface concentrations (Fig. 13b).

With regard to future recovery, on average 2,3,7,8TCDD concentrations in LPR surface sediments should 
continue to decline given the strong regional surface concentration gradient that exists (Fig. 10a), but the rate of that recovery may be slowing and the balance of recovery mechanisms may be shifting over time. It appears likely that the LPR is exhibiting reduced net sedimentation rates due to changing sediment transport patterns associated with the infilling of the lower LPR. Chant et al. (2011) argue that as the channel has accreted toward Newark Bay, a geomorphic equilibrium is being approached due to the reduced trapping efficiency of the lower river; the same infilling effect simultaneously reduces the upstream intrusion of the salt front and presumably the solids delivery to depositional environments in the upper portions of the LPR. Notwithstanding an offsetting effect of future sea level rise due to climate change, a reduction in net sedimentation rates may cause the importance of periodic erosion/deposition and sediment mixing processes to grow in time, and may magnify the impact of historically slower-recovering areas on the mean recovery (i.e., areas with low net sedimentation or recent erosion). For example, the relatively small fraction of 2,3,7,8-TCDD mass trapped upstream may grow in importance to the overall water column response, due to its elevated surface concentrations. Channel migration could perhaps also play a role in altering local recovery rates in the future, to the extent that sustained shifts in net sedimentation/scour patterns occur.

Lastly, it is noted that the extent to which similar recovery dynamics apply to other HOCs residing in the LPR sediment bed depends on the presence/location of ongoing sources and the extent to which LPR concentrations are elevated with respect to regional background levels. While recovery dynamics likely have similarities across multiple HOCs, they are fundamentally HOC specific.

\section{Summary and Conclusions}

The present study demonstrates the use of sediment bed concentrations of a "tracer of opportunity" to gain insight into the dynamics of HOC transport within a complex estuarine system. The approach requires sufficient core data to characterize the longitudinal and vertical distribution of mass inventory of the tracer within the sediment bed, as well as the following prerequisite information: (1) the location and approximate timing of a dominant tracer source; (2) the background concentration of the tracer, or lack thereof; and (3) the approximate timing and extent of anthropogenic disturbances such as dredging events.

In the case of the LPR, the peak 2,3,7,8-TCDD loading associated with past pesticide manufacturing at the Diamond Alkali Superfund Site (i.e., the Lister Avenue site) allowed the integrated transport dynamics over the past 60 years to be studied. The study was aided by the existence of a characteristic fingerprint associated with the LPR 2,3,7,8-TCDD source. Several insights gained are highlighted, as follows:

- HOC trapping processes within the LPR have been highly effective in the past; approximately $3 / 4$ of the LPR/Newark Bay 2,3,7,8-TCDD inventory was estimated to reside in the lower six miles and more than half within approximately 1 mile of the dominant 2,3,7,8-TCDD source location (not accounting for recent removal actions).

- Upstream transport processes (tidal pumping and gravitational circulation) have distributed HOCs as far upstream as approximately RM 14 .

- Trapping of 2,3,7,8-TCDD downstream of RM 2 has likely been more effective than trapping upstream of RM 4 , consistent with expectations based on system geomorphology, the strong influence of freshwater discharge on net sediment transport, and HOC-specific transport processes.

- Although the LPR 2,3,7,8-TCDD signal declines moving away from the LPR mouth (based on concentrations and the ratio of $2,3,7,8-\mathrm{TCDD}$ to total TCDD), the signal remains visible in lower Newark Bay.

- Net sedimentation has been a key driver in the recovery of surface 2,3,7,8-TCDD concentrations in the LPR, influencing both the rate of local recovery and longitudinal trends in mean surface sediment concentrations. While sedimentation has likely been important for other HOCs as well, recovery dynamics are HOC specific in that they depend on the background concentration of the HOC.

Some general limitations of the methods used herein include the following: (1) only long-term net HOC transport may be studied, which may not reflect current conditions (in the case of the LPR, channel infilling is thought to have altered circulation patterns); (2) the relative importance of the dissolved and particulate loads in the water column and the diffusive and particulate flux from the bed cannot be inferred; and (3) competing processes cannot be distinguished (e.g., volumetric dilution; mixing with suspended solids from outside the LPR; sorption dynamics). Moreover, we note that the investigation was aided by past studies and external datasets to evaluate dynamics that cannot be inferred from bed concentrations alone. Overall, we find the method applied herein a useful approach to gaining insights into estuarine dynamics, in particular when paired with other physical data.

Acknowledgments This paper was funded as part of work for the Lower Passaic River Small Parties Group. We thank several past and present colleagues for contributions to analyses, figure development, and text review, including Wen Ku, Mark Meyers, Eben Pendleton, Chantell Owen, Alyssa Thorvaldsen, George Dang, Casey Forrest, Raghav Narayanan, Toni Salvador, Allison Paige, Ricardo Petroni, Peter Oates, 
Undine Kipka, Mark Fabian, and Bin Wang. We also acknowledge insightful technical exchanges on LPR dynamics and historical bathymetry with Rafael Cañizares and Rooni Mathew of Moffatt \& Nichol, as well as with Han Winterwerp and Leo Postma of Deltares. Likewise, we acknowledge helpful interactions on the major datasets with Marcia Greenblatt of Integral Consulting. We further acknowledge Bob Chant of Rutgers University along with coauthors of Chant et al. (2011) for insights therein, and for some clarifications provided. Lastly, we thank two anonymous reviewers for helpful comments on an earlier draft.

Open Access This article is distributed under the terms of the Creative Commons Attribution License which permits any use, distribution, and reproduction in any medium, provided the original author(s) and the source are credited.

\section{References}

Allen, G.P., J.C. Salomon, P. Bassoullet, Y. Dupenhouat, C. Grandpre. 1980. Effects of tides on mixing and suspended sediment transport in macrotidal estuaries. Sedimentary Geology 26: 69-90.

Bedbury, H. 1992. Correspondence. Comment of "A major incident of dioxin contamination: sediments of New Jersey estuaries". Environmental Science and Technology 26(6): 1254-1256.

Belton, T.J., R. Hazen, B.E. Ruppel, K. Lockwood, R. Mueller, E. Stevenson, and J.J. Post. 1985. A Study of dioxin (2,3,7,8tetrachlorodibenzo-p-dioxin) contamination in select finfish, crustaceans and sediments of New Jersey waterways. New Jersey Department of Environmental Protection, Office of Science and Research, October 1985

Bopp, R.F. 1992. Correspondence. Reply to 2nd comment on "A Major incident of dioxin contamination: Sediments of New Jersey estuaries". Environmental Science and Technology 26(6): 1258-1259.

Bopp, R.F., M.L. Gross, H. Tong, H.J. Simpson, S.J. Monson, B.L. Deck, and F.C. Moser. 1991. A major incident of dioxin contamination: Sediments of New Jersey estuaries. Environmental Science and Technology 25(5): 951-956.

Bopp, R.F., S.N. Chillrud, E.L. Shuster, H.J. Simpson, and F.D. Estabrooks. 1998. Trends in chlorinated hydrocarbon levels in Hudson River basin sediments. Environmental Health Perspectives 106(S4): 1075-1081.

Burchard, H., and H. Baumert. 1998. The formation of estuarine turbidity maxima due to density effects in the salt wedge. A hydrodynamic process study. Journal of Physical Oceanography 28: 309-321.

Canizares, R., H. Winterwerp, L. Schmied, and R. Hamson. 2009. Variability of lower Passaic River estuarine dynamics associated with bathymetric uncertainty and dredging. SETAC Annual Meeting 2009

Chaky, D.A. 2003. Polychlorinated biphenyls, polychlorinated dibenzop-dioxins and furans in the New York metropolitan area: Interpreting atmospheric deposition and sediment chronologies. Ph.D. Thesis, Rensselaer Polytechnic Institute, Troy, New York.

Chant, R.J. 2006. The New Jersey toxics reduction workplan for New Yor-New Jersey harbor: study I-E-Hydrodynamic studies in the Newark Bay Complex. April 2006.

Chant, R.J. and A. Stoner. 2001. Particle trapping in a stratified flooddominated estuary. Journal of Marine Research 59: 29-51.

Chant, R.J., D. Fugate, and E. Garvey. 2011. The shaping of an estuarine superfund site: Roles of evolving dynamics and geomorphology. Estuaries and Coasts 34(1): 90-105.

Connolly, J.P., and D. Glaser. 2002. p, p'DDE bioaccumulation in female sea lions of the California Channel Islands. Continental Shelf Research 22: 1059-1078.

Cunningham, J.T. 1966. Newark. New Jersey Historical Society: Newark.
Dronkers, J. 1986. Tidal asymmetry and estuarine morphology. Netherlands Journal of Sea Research 20: 117-131.

Dyer, K.R. 1995. Sediment transport processes in estuaries. Developments in Sedimentology 53: 423-449.

Ehrlich, R., R.J. Wenning, S.H. Johnson, S.H. Shu, and D.J. Paustenbach. 1994. A mixing model for polychlorinated dibenzo-p-dioxins and dibenzofurans in surface sediments from Newark Bay, New Jersey using polytopic vector analysis. Archives of Environmental Contamination and Toxicology 27: 486-500.

Erickson, M.J., C.R. Barnes, M.R. Henderson, R. Romagnoli, and C. Firstenberg. 2007. Geomorphology-based interpretation of sedimentation rates from radiodating, lower Passaic River, New Jersey, USA. Integrated Environmental Assessment and Management 3(2): 166192.

Geyer, W.R. 1993. The importance of suppression of turbulence by stratification on the estuarine turbidity maximum. Estuaries 16(1): $113-125$.

Gillis, C.A., N.L. Bonnevie, S.H. Su, J.G. Ducey, S.L. Huntley, and R.J. Wenning. 1995. DDT, DDD, and DDE contamination of sediment in the Newark Bay estuary, New Jersey. Archives of Environmental Contamination and Toxicology 28(1): 85-92.

Hansen, W.J. 2002. A statistical and spatial analysis of dioxin-furan contamination in the Hudson Estuary. Northeastern Geology and Environmental Sciences 24(3): 159-170.

Hay, A. 1982. The Chemical Scythe-Lessons of 2,4,5-T and Dioxin. Disaster Research in Practice Series. New York: Plenum.

Huntley, S., R.J. Wenning, S.H. Su, N.L. Bonnevie, and D.J. Paustenbach. 1995. Geochronology and sedimentology of lower Passaic River, New Jersey. Estuaries 18(2): 351-361.

Huntley, S.L., T.J. Iannuzzi, J.D. Avantaggio, H. Carlson-Lynch, C.W. Schmidt, and B.L. Finley. 1997. Combined sewer overflows (CSOs) as sources of sediment contamination in the lower Passaic River, New Jersey. II. Polychlorinated dibenzo-p-dioxins, polychlorinated dibenzofurans, and polychlorinated biphenyls. Chemosphere 34(2): 233-250.

Huntley, S.L., H. Carlson-Lynch, G.W. Johnson, D.J. Paustenbach, and B.L. Finley. 1998. Identification of historical PCDD/F sources in Newark Bay estuary subsurface sediments using polytopic vector analysis and radioisotope dating techniques. Chemosphere 36(6): $1167-1185$.

Iannuzzi, T.J., S.L. Huntley, C.W. Schmidt, B.L. Finley, R.P. McNutt, and S.J. Burton. 1997. Combined sewer overflows (CSOs) as sources of sediment contamination in the lower Passaic River, New Jersey. I. Priority pollutants and inorganic chemicals. Chemosphere 34(2): 213-231.

Iannuzzi, T.J., D.F. Ludwig, J.C. Kinnell, J.M. Wallin, W.H. Desvousges, and R.W. Dunford. 2002. A Common Tragedy: History of an Urban River. Amherst: Amherst Scientific Publishers.

Jay, D.A. and J.M. Musiak. 1996. Internal tidal asymmetry in channel flows: origins and consequences. In: Mixing Processes in Estuaries and Coastal Sea, ed. C. Pattiaratchi, Coastal and Estuarine Studies Volume 50: 211-249. American Geophysical Union.

Jay, D.A., R.J. Uncles, J. Largier, W.R. Geyer, J. Vallino, and W.R. Boynton. 1997. Recent developments in estuarine scalar flux estimation. Estuaries 20: 262-280.

Kearney, P.C., E.A. Woolson, A.R. Isensee, and C.S. Helling. 1973. Tetrachlorodibenzodioxin in the environment. Sources, fate and decontamination. Environmental Health Perspectives 5: 273-277.

Le Hir, P., A. Ficht, R.S. Jacinto, P. Lesueur, J.P. Dupont, R. Lafite, I. Brenon, B. Thouvenin, and P. Cugier. 2001. Fine sediment transport and accumulations at the mouth of the Seine estuary (France). Estuaries 24(6B): 950-963.

Lilienfeld, D.E., and M.A. Gallo. 1989. 2,4-D, 2,4,5-T, and 2,3,7,8TCDD: An overview. Epidemiologic Reviews 11: 28-58.

Mathew, R., D Manian, R Cañizares, M Greenblatt, K Cadmus, and J Winterwerp. 2011. Sediment transport processes in the lower 
Passaic River study area. 6th International Conference on Remediation of Contaminated Sediments, New Orleans, LA.

MPI (Malcolm Pirnie, Inc.). 2007. Lower Passaic River Restoration Project, Conceptual Site Model. Prepared for US Environmental Protection Agency, US Army Corps of Engineers, and New Jersey Department of Transportation/Office of Maritime Resources. February 2007.

National Academy of Sciences. 1974. The effects of herbicides in South Vietnam, Part A, Summary and Conclusions. Washington: Committee on the Effects of Herbicides in Vietnam

Pecchioli, J.A., M.S. Bruno, R. Chant, A.M. Pence, A.F. Blumberg, D. Fugate, B.J. Fullerton, S. Glenn, C. Haldeman, E. Hunter, and K.L. Rankin. 2006. The New Jersey Toxics Reduction Workplan for New York - New Jersey Harbor: Study I-E - Hydrodynamic Studies in the Newark Bay Complex. Research Summary, December 2006.

Pence, A.M., M.S. Bruno, A.F. Blumberg, N. Dimou, and K.L. Rankin. 2005. Hydrodynamics governing contaminant transport in the Newark Bay Complex. Proceedings of the Third International Conference on Remediation of Contaminated Sediments, Battelle Press, S.J. Price and R.F. Olfebbuttel (eds.).

Schubel, J.R., and H.H. Carter. 1984. The estuary as a filter for finegrained suspended sediment. In The estuary as a filter, ed. V.S. Kennedy, 81-105. New York: Academic.

Scully, M.E. and C.T. Friedrichs. 2003. The influence of asymmetries in overlying stratification on near-bed turbulence and sediment suspension. Ocean Dynamics 53: 208-219.

Scully, M.E. and C.T. Friedrichs. 2007. Sediment pumping by tidal asymmetry in a partially mixed estuary. Journal of Geophysical Research 112: C07028.

SEI and HQI. 2011. Lower Passaic River: System understanding of sediment transport. Sea Engineering, Inc. and HydroQual, Inc., May 2011.

Shear, N.M., C.W. Schmidt, S.L. Huntley, D.W. Crawford, and B.L. Finley. 1996. Evaluation of the factors relating combined sewer overflows with sediment contamination of the lower Passaic River. Marine Pollution Bulletin 32(3): 288-304.

Silbergeld, E.K., M. Gordon, and L.D. Kelly. 1993. Dioxin at diamond: A case study in occupational/environmental exposure. In Toxic Circles, Environmental Hazards from the Workplace into the Community, ed. H.E. Sheehan and R.P. Weeden. New Brunswick, New Jersey: Rutgers University Press.

Sommerfield, C. and R.J. Chant. 2010. Mechanisms of Trapping and Accumulation in Newark Bay, New Jersey: An Engineered Estuarine Basin (HRF 008/07A). Report to the Hudson River Foundation HRF Project 008/07A.

Sormunen, A.J., M.T. Leppanen, and J.V.K. Kukkonen. 2009. Desorption and bioavailability of spiked pentabromo diphenyl ether and tetrachlorodibenzo(p)dioxin in contaminated sediments. Archives of Environmental Contamination and Toxicology 56: 670-679.

Tong, H.Y., S.J. Monson, M.L. Gross, R.F. Bopp, H.J. Simpson, B.L. Deck, and F.C. Moser. 1990. Analysis of dated sediment samples from the Newark Bay area for selected PCDD/Fs. Chemosphere 20(10-12): 1497-1502.

TSI (Tierra Solutions Inc.). 2008. Phase I Engineering Evaluation/Cost Analysis. CERCLA Non-Time-Critical Removal Action - Lower Passaic River Study Area. November 2008.
TSI. 2011a. Newark Bay Study Area-Interim Conceptual Site Model. February 2011, Revision 1.

TSI. 2011b. Phase I and Phase II Sediment Deposition Report. Newark Bay Study Area Remedial Investigation. October 2011, Revision 1.

Umbreit, T.H., E.J. Hesse, and M.A. Gallo. 1986. Bioavailability of dioxin in soil from a $2,4,5-\mathrm{T}$ manufacturing site. Science 232(4749): 497-499.

Uncles, R.J., and J.A. Stephens. 1989. Distributions of suspended sediment at high water in a macrotidal estuary. Journal of Geophysical Research 94(C10): 14,395-14,405.

Uncles, R.J., R.C.A. Elliott, and S.A. Weston. 1985. Observed fluxes of water, salt and suspended sediment in a partly mixed estuary. Estuarine, Coastal and Shelf Science 20(2): 147-167.

Uncles, R.J., J.A. Stephens, and T.Y. Woodrow. 1988. Seasonal cycling of estuarine sediment and contaminant transport. Estuaries 11(2): 108 116.

USACE. 2010. Lower Passaic River Commercial Navigation Analysis. Rev. July 2010.

USACE (U.S. Army Corps of Engineers). 2007. Environmental Assessment. Effects of the NY/NJ Harbor Deepening Project on the Remedial Investigation/Feasibility Study of the Newark Bay Study Area. June 2007.

USEPA (U.S. Environmental Protection Agency). 2008. Diamond Alkali Co. Superfund Site Fact Sheet. http://www.epa.gov/region02/ superfund/npl/0200613c.pdf.

Wakeman, T.H., A.F. Blumberg, D.B. Kruger, and A.M. Fullerton. 2007. Sediment movement and dredging in Newark Bay, NJ. Proceedings of Ports 2007: 30 years of sharing ideas, 1977-2007. March 25-28, 2007, San Diego, CA.

Wenning, R.J., M.A. Harris, M.J. Ungs, D.J. Paustenbach, and H. Bedbury. 1992. Chemometric comparisons of polychlorinated dibenzo-p-dioxin and dibenzofuran residues in surficial sediments from Newark Bay, New Jersey and other industrialized waterways. Archives of Environmental Contamination and Toxicology 22(4): 397-413.

Wenning, R., D. Paustenbach, G. Johnson, R. Erlich, M. Harris, and H. Bedbury. 1993a. Chemometric analysis of potential sources of polychlorinated dibenzo-p-dioxins and dibenzofurans in surficial sediments from Newark Bay, New Jersey. Chemosphere 27(1-3): $55-64$.

Wenning, R.J., M.A. Harris, B. Finley, D.J. Paustenbach, and H. Bedbury. 1993b. Application of pattern recognition techniques to evaluate polychlorinated dibenzo-p-dioxin and dibenzofuran distributions in surficial sediments from the lower Passaic River and Newark Bay. Ecotoxicology and Environmental Safety 25(1): 103-125.

Winterwerp, J.C. 2011. Fine sediment transport by tidal asymmetry in the high-concentrated Ems River: indications for a regime shift in response to channel deepening. Ocean Dynamics 61(2-3): 203-215.

Worthington, J.B. 1983. Director of Environmental Affairs, Diamond Shamrock. Letter to Michael Catania, New Jersey Department of Environmental Protection.

Yu, Q., Y.P. Wang, B. Flemming, and S. Gao. 2012. Tide-induced suspended sediment transport: Depth-averaged concentrations and horizontal residual fluxes. Continental Shelf Research 34: 53-63. 